\title{
Evaluación organizacional del Programa de Modernización Administrativa del D.D.F.
}

David Arellano Gault. Colaboración: Jorge E. Culebro Moreno y Miguel A. Gutiérrez

\section{Introducción ${ }^{1}$}

En 1995 el Jefe del Departamento del Distrito Federal a través de la Oficialía Mayor puso en marcha un ambicioso programa de modernización de los órganos encargados del gobierno de la ciudad de México. Las especificidades de este Programa de Modernización Administrativa (PMA) ${ }^{2}$ pueden considerarse innovadoras desde diversos puntos de vista.

En términos generales, la principal característica innovadora de este PMA fue que busca generar un cambio cualitativo en la cultura organizacional dentro de las estructuras administrativas del órgano de gobierno de la ciudad: el Departamento del Distrito Federal (D.D.F.). Y lo busca hacer no sólo a través de una reorientación de la actitud del servidor público hacia los ciudadanos, de una reestructuración organizacional, de la simplificación administrativa y de una mejora constante en los indicadores del desempeño, sino también a través de una reformulación del papel de la Administración como agente social.

El PMA partió de una reformulación filosófica respecto a la forma de observar a la parte administrativa del gobierno de una ciudad: esta parte administrativa es ante todo un ente coadyuvante al desarrollo de las actividades de los particulares. Lo 'es ño sólo bajo una visión de laissez faire sino también bajo una visión de responsabilidad, de regulación, de equidad. Pero sustantivamente eso, no una Administración que limita y estorba la actividad de los particulares, sino que es un apoyo, un es- pacio institucional facilitador de la actividad propia de los ciudadanos.

Alcanzar esta misión, es decir, generar un gobierno que en su parte administrativa sea coadyuvante y responsable, requiere del desarrollo de dos grandes actividades. Necesariamente una reformulación del marco jurídico y normativo. Aunado a ello, una transformación de la cultura organizacional que permitiera, a través de la participación sustantiva de los servidores públicos, generar una respuesta de calidad a las demandas ciudadanas.

La primera, con el fin de redefinir los alcances y potencialidades del accionar gụbernamental, otorgándole a los ciudadanos y a los servidores públicos las herramientas y el marco de referencia que facilite una relación ágil, de confianza y cooperación. La segunda, con el objetivo de transformar las estructuras, valores y símbolos organizacionales.

El PMA que surgió a principios de 1995 nació con esta filosofía y fue impulsado a través de un intenso proceso de implementación en todas las estructuras del D.D.F.: centralizadas y desconcentradas (es decir, en las Delegaciones) ${ }^{3}$. Y fue hecho bajo condiciones excepcionales, tanto en términos económicos como políticos.

En este sentido es importante considerar que la Administración que diseñó e impulsó el PMA se hallaba inmersa en un proceso muy complejo de transición política ${ }^{4}$. En términos específicos, estas transformaciones contextuales implicaron que la administración del D.D.F. haya tenido sólo tres años para desarrollar sus programas y lo hizo en un ambiente político alta- 
mente sensible y complejo ante los cambios políticos que se vivieron en la Ciudad de México.

Es bajo este marco que la presente investigación se desarrolló. Pareciera válido asumir que es intrínsecamente trascendente estudiar la modernización administrativa del gobierno de una ciudad como el Distrito Federal. Sin embargo, dadas las condiciones contextuales extraordinarias que se han expuesto, y la especial filosofía que le dio sentido e intención al programa, el estudio adquiere características particulares.

El objetivo del presente estudio fue analizar y evaluar las estrategias a través de las cuales el PMA fue implementado. La finalidad de este análisis fue obtener lecciones para entender diferentes esfuerzos de modernización administrativa de metrópolis, en condiciones similares. De este análisis y de los juicios de evaluación que se generen, se obtienen perspectivas y enseñanzas prácticas que pueden ser útiles para entender los procesos de modernización administrativa en metrópolis. Particularmente, se consideró que evaluar las virtudes de tales estrategias con el fin de alcanzar permanencia e institucionalización de los comportamientos y estructuras organizacionales reformulados surge como una tarea importante a desarrollar. Estos estudios pueden otorgar pistas respecto a los obstáculos y resistencias que las estrategias de modernización deben enfrentar para alcanzar resultados. Siendo que éstos no son sólo de mejora de los indicadores del desempeño, sino de transformación de la cultura legal y organizacional, esta investigación puede otorgar información importante respecto a las capacidades de permanencia e institucionalización de nuevas actitudes organizacionales a través de programas generales de modernización.

Este análisis tomó en cuenta una serie de condiciones contextuales - mencionadas anteriormente- que afectan y limitan las interpretaciones y el análisis. Se debe de tener claro que se estudió una experiencia de modernización en sus fases iniciales. No es posible considerar que una organización del tamaño y complejidad del D.D.F. pueda cambiar radicalmente en tan sólo dos años. Así, se asumió que se analizaría una experiencia que está en proceso de institucionalización. Los cambios observados se toman en consideración como tales, es decir, como cambios parciales en un proceso de implementación actual y de temprana institucionalización.

Las conclusiones que se deriven de este estudio no pueden ser definitivas. Más que realizar una evaluación terminal, lo que se persigue es establecer una evaluación que sistematice una serie de lecciones importantes para la comprensión de otras experiencias similares. La complejidad contextual, política y administrativa, hacen de este trabajo algo interesante en la medida en que se observaron condiciones extraordinarias sobre las cuales un esfuerzo de modernización se implementó. Pero tales complejidades contextuales implicaron también límites impor- tantes al presente documento, algunos de los cuales son indispensables hacer explícitos.

La crisis y el proceso de transición política constituyen un espacio particularmente dinámico para el comportamiento de los actores involucrados. La generación de nuevas reglas, el cambio de patrones de comportamiento, la transformación de las expectativas políticas, fueron algunos de los elementos que sin duda afectaron al proceso de modernización administrativa. En resumen, se observaron comportamientos especiales en circunstancias extraordinarias. El peso de estas condiciones fue sin duda importante en el momento de realizar las interpretaciones particulares sobre el cambio y el proceso de institucionalización que se sugirió.

Es importante considerar las limitantes particulares sobre las que este estudio se realizó. Dadas las restricciones de recursos y de tiempo, el análisis podía desarrollarse en un lapso máximo de cinco meses. Esto implicó que el estudio debería encontrar una fórmula metodológica para escoger una muestra significativa, ante la imposibilidad de analizar en términos generales al D.D.F.

A partir de estas consideraciones, se escogió realizar el estudio de dos casos. Se buscaron situaciones donde el proceso de modernización fuera considerado por los propios reformadores como casos en los cuales el PMA se encontrara más avanzado. Dados los límites de tiempo se asumió que es más útil estudiar los casos de éxito que aquellos no tan avanzados, no porque estos últimos no otorguen lecciones, sino porque no se buscó establecer un juicio terminal sobre la experiencia de modernización. Sólo se intentó encontrar lecciones y perspectivas para el entendimiento de experiencias similares de modernización en metrópolis. Las lecciones, límites y perspectivas de una experiencia de modernización exitosa parecieran ser las más útiles en estos términos.

De esta manera, se decidió que se estudiarían dos casos de implementación del PMA en el sector desconcentrado (Delegaciones políticas) del D.D.F. Un caso donde el proceso fue implementado sistemáticamente, sin cambios políticos y administrativos internos de consideración, y otro donde estos cambios (por ejemplo, cambios de autoridades de alto nivel) se observaron y aun así la implementación del PMA avanzó. El primer estudio de caso es el "normal", es decir que, dada la complejidad contextual ya establecida, el proceso fue instrumentado continuamente sin mayores afectaciones. El segundo caso es el que denominamos "caso de control, donde los cambios de autoridades se percibieron y donde, sin embargo, el proceso ha continuó sistemáticamente. Dada la importancia que se le da en el estudio al análisis de la institucionalización de los cambios, esta situación extrema otorga lecciones importantes para futuras experiencias de modernización. En concreto, los casos de estudio que se presentan comesponden a la Delegación Álvaro Obregón (caso enormal.) y a la Delegación Venustiano Carranza (caso ade control"). 
Como puede deducirse, este análisis enfrentó una serie de retos importantes. El realizar un estudio de evaluación de un programa de modernización de recién implementación, que fue desarrollado en condiciones políticas y administrativas extraordinarias, y el poco tiempo que se tuvo disponible para el estudio, implicaron las limitaciones mencionadas. Sin embargo, consideramos que el estudio sistemático de experiencias de modernización en metrópolis siempre enfrentará complejidades y dificultades. En todo caso, lo que se busca es ir desarrollando estudios empíricos de los cuales se pueden obtener lecciones y perspectivas para el entendimiento de procesos de modernización en contextos particulares.

El presente documento está organizado en cuatro partes. La primera parte sintetiza los elementos que consideramos sustantivos del PMA. Se definen las acciones estratégicas desarrolladas, así como la filosofía que ha guiado al propio proceso de modernización. El objetivo de esta primera parte es ubicar las expectativas y orientaciones generales que conforman el PMA con el fin de tener un parámetro claro de comparación y análisis respecto a los resultados obtenidos en los casos. Las partes segunda y tercera refieren a los estudios de caso mencionado. En estos estudios de caso se analiza el proceso de implementación del PMA en condiciones particulares. Se enfatiza el análisis de la propensión al cambio en la cultura organizacional así como de las perspectivas de institucionalización de los mecanismos y símbolos generados por el propio programa de modernización.

El objetivo de los casos es observar el desempeño organizacional de las Delegaciones, estudiar la transformación de los símbolos organizacionales que los servidores públicos internalizan así como los mecanismos organizacionales que puedan dar permanencia a este cambio. En otras palabras, el énfasis de los estudios de caso se encuentra en el análisis de las perspectivas de permanencia e institucionalización que el PMA fue capaz de generar, considerando que este elemento (la posibilidad de permanencia de las nuevas actitudes y espacios organizacionales) son un concepto clave para evaluar el éxito del programa más allá de los indicadores del desempeño. Estas partes mantienen un sentido básicamente descriptivo con el fin de facilitar la comparación entre casos y entre éstos y el programa. Es a través de estas comparaciones que un análisis sistemático y metodológicamente congruente puede ser realizado.

En la última parte se desarrollan las conclusiones y se proponen una serie de lecciones que este tipo de estrategias de modernización pueden generar para experiencias metropolitanas similares. Como se mencionó, estas conclusiones emergen de la comparación entre los casos de estudio y entre éstos y el programa (en términos de congruencia y alcance). Con el fin de facilitar la lectura del presente documento, la parte metodológica es desarrollada en un apéndice metodológico que posiblemente otorgue mayor claridad respecto a las perspectivas de análisis y observación así como a las categorías utilizadas para el desarrollo de la presente investigación.

\section{Antecedentes del Programa de Modernización}

El Programa de Modernización Administrativa (PMA) que el Departamento del Distrito Federal (D.D.F.) puso en marcha fue desarrollado de manera congruente con el Plan Nacional de Desarrollo 1995-2000.

La Oficialía Mayor del D.D.F. - a través de la Dirección General de Modemización Administrativa - coordinó el PMA; la Contraloría General participó en la implementación del Programa de Calidad y Excelencia, que fue una de las vertientes del PMA.

El PMA partió de una serie de preocupaciones tales como cuál debe ser el papel de las instituciones públicas ante los nuevos escenarios internacionales y las nuevas realidades nacionales y qué tipo de instituciones públicas debe tener la Administración Pública moderna. De estos planteamientos y sus respuestas surgió un programa que busca sistemáticamente la eficiencia, el alto desempeño y la participación de la sociedad. De la misma manera, el PMA aspiró a generar un nuevo tipo de institución pública flexible, que lograra adaptarse con rapidez a los cambios frecuentes de entorno y de las demandas y que pudiera tener costos de administración razonables. En resumen, instituciones públicas fuertes, eficaces, flexibles y promotoras.

Los principales objetivos del programa en términos generales pueden resumirse como sigue:

- Adecuar la Administración Pública a la nueva situación jurídico política del D.F.

- Fortalecer las instituciones públicas del D.F., modernizando sus estructuras orgánicas, actualizando su marco juridico, rediseñando sus procesos sustantivos, ampliando la capacidad tecnológica y utilizando eficientemente los recursos públicos.

- Incrementar la efectividad de las dependencias y su capacidad de respuesta a demandas cambiantes, asi como mejorar la prestación de los servicios, elevando su calidad y cobertura, buscando satiffacer los requerimientos de los ciudadanos.

- Revalorar el servicio público, reforzando los valores de patriotismo, bonestidad y responsabilidad y estimulando nuevos valores como la creatividad y la innovación. 
- Crear un nuevo ambiente laboral basado en la colaboración, la productividad y el reconocimiento al desempeño y la innovación.

- Mejorar la productividad de la ciudad creando un marco regulatorio que promueva e incentive la inversión y el desarrollo económico ${ }^{5}$. fueron:

Lo anterior se concretizó en ocho vertientes de trabajo que

1) Desregulación: Modernización del marco normativo para promover e impulsar las actividades productivas del D.F.

2) Clarificación administrativa: Proporcionar información clara y oportuna enfocada a proveer al ciudadano de elementos que faciliten su relación con la Administración Pública.

3) Sistema de Atención al Ciudadano: Mejorar el sistema de Ventanillas Únicas Delegacionales y la creación de los Centros de Servicios y Atención Ciudadana.

4) Estructuras orgánicas: Adecuar las estructuras a fin de evitar excesivos niveles de mando con cortos tramos de control.
5) Automatización de procesos: Uso de herramientas de vanguardia que permitan brindar un servicio rápido y eficiente.

6) Sistema social: Generar un cambio cultural entre los servidores públicos del D.D.F.

7) Indicadores y estándares: Establecer un sistema de medición cuyo objetivo es incrementar los niveles de eficiencia de los servicios.

8) Calidad y excelencia: Mejora de los procesos que lleva a cabo el D.D.F. partiendo de una nueva cultura de servicio.

Estas ocho vertientes tuvieron avances diversos. Sin embargo fueron dos las grandes estrategias que le han dado impulso y sentido, permeando a las ocho vertientes. Estas dos estrategias básicas de acción se generaron como puntas de lanza para darle vida al programa. Primero, una transformación del marco juŕdico que permitiera conformar a la administración del gobiemo como un facilitador de las actividades de los particulares, de los ciudadanos. Segundo, una transformación de la cultura organizacional que dirigiera el comportamiento de los servidores públicos hacia valores como la calidad y la excelencia (cuadro 1).

\begin{tabular}{|c|c|c|}
\hline \multicolumn{3}{|c|}{ 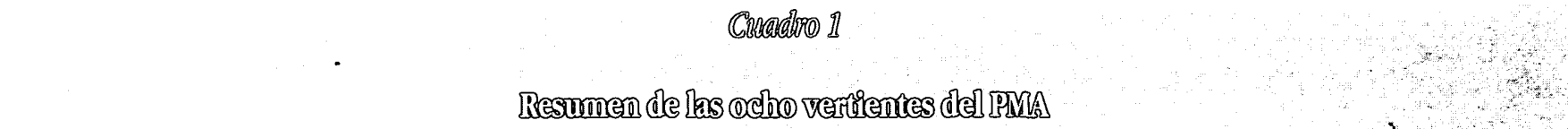 } \\
\hline Vertientes & Objetivos & Acciones \\
\hline Desregulación Administrativa & $\begin{array}{l}\text { - Revisión y actualización del marco normativo } \\
\text { orientado a principios jurídicos de simplificación, } \\
\text { agilidad, información, precisión, legalidad, trans- } \\
\text { parencia, imparcialidad, buena fe y autocontrol de } \\
\text { los particulares. }\end{array}$ & $\begin{array}{l}\text { - Ley de Procedimiento Administrativo. } \\
\text { - Ley para el Funcionamiento de Establecimientos } \\
\text { Mercantiles. } \\
\text { - Ley para el Desarrollo Urbano. } \\
\text { - Ley Ambiental del Distrito Federal. } \\
\text { - Ley de Protección Civil del Distrito Federal. } \\
\text { - Reglamento de Verificación Administrativa. } \\
\text { - Sistema de Apertura Inmediata de Empresas. }\end{array}$ \\
\hline Clarificación Administrativa & $\begin{array}{l}\text { Proporcionar información oportuna sobre los } \\
\text { trámites y servicios que proporciona el D.D.F. } \\
\text { para fortalecer su posición y facilitar su rela- } \\
\text { ción con la Administración Pública. }\end{array}$ & $\begin{array}{l}\text { - Publicación de decretos, acuerdos, circulares, } \\
\text { - } \text { Expedición del Manual de Trámites y Servicios al } \\
\text { público. } \\
\text { - Disponibilidad del Manual de Trámites y Servicios } \\
\text { al Público en Internet y disquetes. } \\
\text { - Difusión de los trámites de mayor demanda, de la } \\
\text { Ley de Procedimiento Administrativo, del Manual } \\
\text { de Trámites y Servicios al Público, del procedimiento } \\
\text { de acceso a expedientes y de la afirmativa ficta. } \\
\text { - Señalización para la orientación del ciudadano en } \\
\text { las VUD de acuerdo a su imagen corporativa. } \\
\text { - Servicio de información sobre trámites, TRAMITEL } \\
\text { de LOCATEL. }\end{array}$ \\
\hline Sistemas de Atención al Público & - Mejorar la calidad de la atención al ciudadano. & 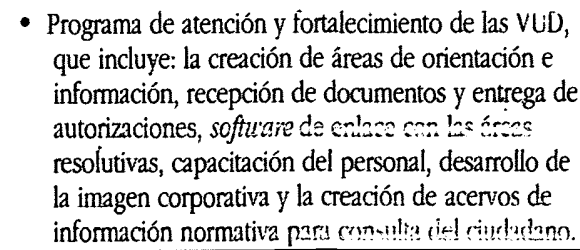 \\
\hline
\end{tabular}




\section{Curachero I]}

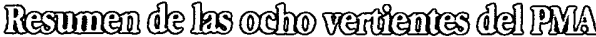
(Continuacion)

\section{Vertientes}

Objetivos

Acciones
Sistemás de Atención al Puiblico

(cont.)

\section{Estructuras Orgánicas}

Tecnología

Sistema Social

Indicadores y Eständares

Calidad y Excelencia
- Diseñar estructuras organizacionales que permitan responder a los cambiantes escenarios nacionales e internacionales.

Agilizar la operación de los procesos de alto impacto en la ciudadanía.

- Sembrar la semilla del cambio cultural.

- La medición y evaluación de la gestión pública, para la mejora continua.

- Mejorar sustancialmente la calidad del servicio a la ciudadanía a través de:

- Rediseño de procesos sustantivos que buscan la satisfacción del ciudadano, la eliminación de requisitos y la automatización de procesos rediseñados.

- Cambio cultural con un enfoque $100 \%$ participativo, trabajo en equipo, iniciativa propia, habilidades y facultación y mejora continua.
- Creación del Centro de Servicios y Atención a la Demanda ciudadana (CESAC) en las Delegaciones que permiten recabar, clasificar, gestionar y dar respuesta a la demanda ciudadana.

- Elaboración de una metodología para el diseño y rediseño de las estructuras y definición de 4 modelos organizacionales: por procesos, por servicios, por segmento de mercado y por usuario.

- Adopción de una política de no crear Jefaturas de Unidad Departamental.

- Impulso a la creación de estructuras basadas en equipos de trabajo con personal multihabilidades.

- Desconcentración de facultades a las Delegaciones.

- Sistema Automatizado de Ventanilla Única.

- Sistema de Información Geográfica y de Suelo.

- Sistema Delegacional de Verificación Empresarial.

- Sistema de Registro y Control del Comercio Ambulante.

- Sistema de administración de recursos humanos desconcentrado.

- Sistema de registro y control de la demanda ciudadana.

- Adquisición de equipo de cómputo, tendido de redes y desarrollo de sistemas.

- Creación de equipos de trabajo que identifican la problemática, proponen soluciones y las implantan.

- Equipos de trabajo que rompen las barreras que segmentan los procesos por funciones o departamentos, integrando a diferentes niveles jerárquicos y áreas de la institución.

- Desarrollo de habilidades y facultación.

- Mejora continua.

- Creación de la unidad de Profesionalización de los Servidores Públicos del D.D.F

- Realización de conferencias de sensibilización y cursos/taller.

- Cada unidad administrativa definió sus indicadores.

- Inicio de un proceso de mejora continua.

- Selección de los procesos críticos o de alto impacto aplicando los criterios de visibilidad, productividad, oportunidad, factibilidad y multiplicabilidad.

- Rediseño e implantación de los procesos de: Atención a la Demanda Ciudadana, Resolución de Trámites, Mantenimiento Urbano y Mantenimiento a Edificios

Públicos.

- Rediseño e implantación en el Sector Central. de 23 procesos originales, 25 procesos vigentes, 22 procesos en desarrollo y tres procesos iniciando su desarrollo.

- Rediseño e implantación de los procesos horizontales de Desconcentración de la Administración de Recursos Humanos, Programas Operativos Anuales y Simplificación de Adquisiciones.

- Más de 80 equipos de trabajo y aproximadamente 1.300 personas trabajando coordinadamente.

- Creación de Centros de Servicios y Atención Ciudadana.

- Reorganización de la Ventanilla Única.

- Simplificación de procedimientos y dictaminación de trámites 
Curadro I

\begin{tabular}{|c|c|c|}
\hline \multicolumn{3}{|c|}{ 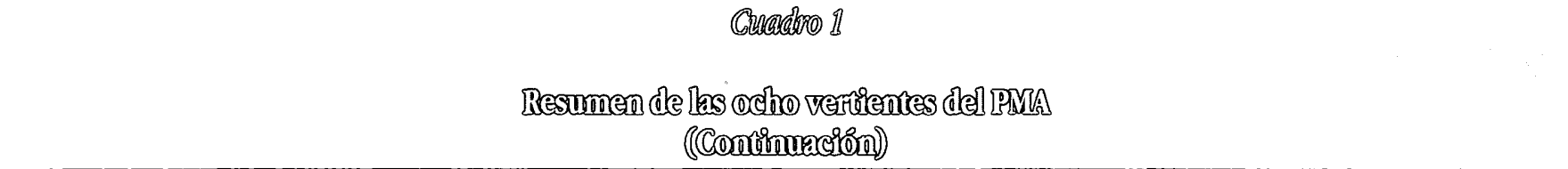 } \\
\hline Vertientes & Objetivos & Acciones \\
\hline $\begin{array}{l}\text { Calidad y Excelencia } \\
\text { (cont.) }\end{array}$ & & $\begin{array}{l}\text { - Identificación de las necesidades de mantenimiento. } \\
\text { - Redistribución de responsabilidades. } \\
\text { - Elaboración de manuales de uso de instalaciones. } \\
\text { - Establecimiento de indicadores claves de desempeño. } \\
\text { - Diseño de mejores procedimientos de asignación de } \\
\text { tareas a las unidades operativas. } \\
\text { - Programa integral de Capacitación en cultura de la } \\
\text { calidad. } \\
\text { - Programa de reconocimiento y estímulos. } \\
\text { - Programa de difusión en Calidad y Excelencia. }\end{array}$ \\
\hline
\end{tabular}

Para lograr lo primero se revisó y cambió el marco jurídico que norma a las instituciones públicas de la ciudad, ya que muchas veces estos sistemas normativos y de control inhiben el desarrollo de las instituciones y hacen que los costos se eleven. Por lo tanto, era necesario revisar el marco jurídico, el esquema de responsabilidades y los sistemas de control. Esta visión estuvo orientada a crear instituciones que pudieran trabajar en función de principios de confianza, de auto control y no bajo aquellos de desconfianza y de permanente supervisión externa.

Para alcanzarlo se transformó el marco legal que norma a las instituciones y hacen que los costos se eleven; por lo que fue necesario revisar los marcos jurídicos, el esquema de responsabilidades y los sistemas de control. Respecto al logro de una transformación de los valores de la cultura organizacional, se definió como indispensable el cambio de la cultura burocrática para establecer una nueva visión basada en una actitud de los servidores públicos dirigida bajo parámetros de calidad y excelencia en el trabajo.

\subsection{Programa de Desregulación y Simplificación Administrativa (PDSA)}

El proceso de transición política suponía la revisión del marco jurídico en particular. Muchas leyes tuvieron que adecuarse al nuevo status jurídicopolítico del D.F. Ello implicó areconstruir" el marco jurídico en un plazo de tiempo reducido. Ante esta coyuntura se revisó y modificó el esquema legal de la Administración del D.D.F. Pero además se realizó bajo un enfoque desregulador que mantuvo como filosofía central que la Administración no debía de ser un estorbo sino un facilitador de las actividades de los ciudadanos.

En este contexto, el propósito fundamental del PDSA fue liberar las energías de la sociedad para crear un ambiente más favorable para la inversión y el empleo, convirtiendo a la Admi- nistración del D.D.F. en una palanca de desarrollo de la ciudad. De la misma manera, se buscó eliminar normas jurídicas obsoletas que regulaban en exceso las actividades de los particulares y que no aclaraban el papel y los procedimientos de los órganos administrativos, propiciando excesiva discrecionalidad y convirtiéndose en el principal obstáculo para la modernización. Es decir, la regulación excesiva distorsionaba e influía negativamente en el desempeño de una economía moderna de mercado.

La puesta en operación del PDSA se llevó a cabo en tres etapas: La primera comenzó el 16 de mayo con el fin de otorgar facilidades administrativas y subsidios fiscales para la creación, regularización y funcionamiento de las micro, pequeñas y medianas empresas. La segunda se integró con un conjunto de acciones de desconcentración y simplificación administrativa que entraron en vigor el 3 de julio de 1995. La tercera se inició en noviembre y diciembre de 1995 que implicó la revisión, elaboración y adecuación de diversos ordenamientos jurídicos, la cual está concluyendo ${ }^{6}$.

Una de las principales acciones del PDSA fue la creación de la Ley de Procedimiento Administrativo del Distrito Federal (LPA ${ }^{7}$, que fue una síntesis de dos proyectos: uno de ellos elaborado por la Dirección de Normatividad Administrativa en el primer semestre de 1995 y el otro por la Comisión de Administración Pública Local de la Asamblea de Representantes. El proyecto final se aprobó el 22 de noviembre de 1995. La Ley entró en vigor un mes después, salvo los artículos relativos a la afirmativa ficta $^{8}$, que entraron en vigor en julio de 1996. Su importancia radicó en que por primera vez se contó con un instrumento jurídico globalizador orientado a facilitar la reforma de la Administración Pública del D.F.

En síntesis, en el PDSA se distinguieron dos elementos: El primero de ellos fue la expedición y actualización de leyes y reglamentos basados en principios novedosos (como la buena fe y la afirmativa ficta) que dan más certidumbre al particular y favorecen las actividades económicas en la ciudad. El segundo 
consistió en la revisión, compilación, unificación y en particular la difusión de los requisitos de los trámites de tal manera que sean homogéneos, evitando la excesiva discrecionalidad por parte de lós servidores públicos. Ambos elementos se suistentan en el grado de riesgo, en la autorregulación, en la claridad y simplificación de los trámites, en la afirmativa ficta y en la desconcentración a las Delegaciones.

Lo anterior se concretizó, por una parte, en la atención al público en la Ventanilla Única Delegacional (VUD), cuyo objeto fue que la ciudadanía efectuara en un solo lugar sus trámites y gestiones a través de procedimientos transparentes y ágiles evitando que acudiera a las áreas dictaminadoras para eliminar la discrecionalidad; y por otra, en el Centro de Servicios y Atención Ciudadana (CESAC), con la finalidad de concentrar en un solo punto la recepción, seguimiento y canalización de las demandas de la ciudadanía que anteriormente se hacía a través de otras instancias, como la oficina del Delegado y las Subdelegaciones correspondientes. Ambas instancias sirvieron para mejorar la imagen de los servidores públicos ante la ciudadanía, pues, a dife- rencia de las áreas dictaminadoras y operativas, su personal se capacitó específicamente para la atención al público.

\subsection{Programa de Calidad y Excelencia (PCE)}

El PCE tuvo la intención de implantar una cultura de la calidad principalmente a través de la reingeniería de procesos en Delegaciones y en áreas centrales del gobiemo capitalino, generando una dinámica de mejora continua y de aprendizaje permanente en todos los espacios organizacionales que componen al D.D.F.

Así, se buscó la satisfacción del ciudadano como último propósito a alcanzar, de una manera continua y sistemática. Para ello, los valores que se intentaron sembrar fueron, por una parte, la atención al ciudadano, la oportunidad en el servicio, la información completa, el respeto a los tiempos de respuesta y, por la otra, que el servidor público tuviera una actitud de auto desarrollo, de auto control y de auto valoración de su trabajo (cuadro 2).

\section{Cunculdro 2}

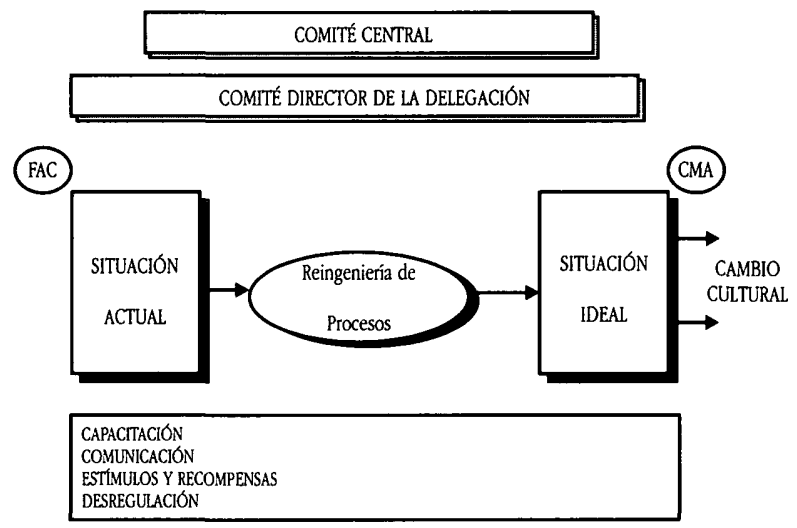

Nota: $\mathrm{FAC}=$ Factibilidad $\mathrm{CMA}=$ Coordinador de Modernización Administrativa

El PCE partió de tres premisas:

1) El gobierno del D.F. se ha propuesto desarrollar una cultura de calidad y excelencia que se transforme en una mayor productividad, eficacia y eficiencia.

2) Los servidores públicos del D. F. desean mejores condiciones de trabajo, dentro de un ambiente de cooperación a todos los niveles de la organización y la oportunidad de ser protagonistas de los cambios en la cultura organizacional.

3) Los cambios necesarios se apoyan en los esfuerzos destinados a la desregulación, simplificación, clarificación y descentralización.
La reingeniería de procesos fue el instrumento utilizado para llevar al cabo el PCE, asumiendo que es una herramienta que logra cambios radicales en los procesos sustantivos de una institución en períodos cortos de tiempo. Debe destacarse, sin embargo, que paralelamente se llevaron a la práctica estrategias de capacitación y de comunicación interna con la intención de fortalecer el proceso de transformación cultural y de esta manera hacer de la reingeniería un instrumento efectivo.

El PCE se inició formalmente en mayo de 1995. Con la finalidad de institucionalizarlo se creó la Dirección de Calidad (15 de septiembre de 1996) y la figura del Coordinador de Modernización 
Aclministrativa, quien fue el administrador del Programa en cada Delegación. En un principio el Coordinador participó en los equipos de rediseño para aprender la metodología. Gradualmente el Programa quedó bajo su responsabilidad en la Delegación, teniendo como obligaciones preparar las sesiones de trabajo, documentarlas, darles seguimiento y asesorar al programa. Asimismo, es necesario mencionar otro actor institucional del PCE, el facilitador, adscrito a la coordinación de reingeniería de procesos en Delegaciones. Su función fue ayudar al desarrollo de las sesiones de trabajo sin participar de manera permanente en las Delegaciones, con el fin justamente de facilitar el proceso de institucionalización de los principios del Programa desde las propias organizaciones.

En la primera fase se detectaron cuáles eran los procesos claves susceptibles de rediseñarse; sin embargo, hay que destacar que la revisión documental y las entrevistas a funcionarios y al público arrojaron como resultado un gran número de procesos susceptibles de rediseñarse. Por ello se sometieron a una selección con la intención de quedarse con los de alto impacto que en este caso fueron cuatro. Los criterios de selección fueron los siguientes: visibilidad (que los servidores públicos y la ciudadanía pudieran notar los cambios); productividad (que al rediseñar el proceso se pudiera hacer más con lo mismo o con menos); oportunidad (que se pudiera realizar en el corto plazo); factibilidad (que hubiera todos lo elementos necesarios para realizar el rediseño) y multiplicabilidad (que el proceso rediseñado pudiera ser exportado a otras Delegaciones). Los cuatro procesos de alto impacto que se seleccionaron fueron: Atención a la Demanda Ciudadana (antes Control de Gestión); Resolución de Trámites (antes Ventanilla Única Delegacional); Mantenimiento Urbano (antes Mantenimiento de Servicios Urbanos) y Mantenimiento a Edificios Públicos (antes Mantenimiento a Escuelas) ${ }^{9}$.

El PCE se implementó también en el sector central en las Secretarías de Desarrollo Urbano y Vivienda; Educación, Salud y Desarrollo Social; Finanzas; Gobierno; Medio Ambiente; Obras; Seguridad Pública; Transporte y Vialidad; Contraloría General y Oficialía Mayor. En el sector desconcentrado (Delegaciones) se puso en práctica de manera piloto en dos delegaciones: Azcapotzalco y Álvaro Obregón. Después se extendió a otras seis Delegaciones (Benito Juárez, Iztapalapa, Magdalena Contreras, Tlalpan y Venustiano Carranza) y posteriormente al resto (Coyoacán, Cuajimalpa de Morelos, Cuauhtémoc, Iztacalco, Milpa Alta, Tláhuac y Xochimilco). Además, se instrumentaron tres procesos horizontales, que fueron: Desconcentración de la Administración de Recursos Humanos; Programas Operativos Anuales y Simplificación de Adquisiciones. En las Delegaciones, el PCE inició en mayo de 1995; en las otras dos áreas, en noviembre del mismo año.

\section{Caso de Estudio. Delegación Álvaro Obregón}

\subsection{Modernización administrativa de la Delegación Álvaro Obregón: Objetivos y elementos estratégicos}

El Programa de Modernización Administrativa siguió un proceso de inducción de sus ocho vertientes y a partir de sus dos estrategias clave, para ser instrumentado en la Delegación Politica Álvaro Obregón. Como se ha señalado, la aplicación del Programa de Calidad y Excelencia (PCE) en esta Delegación tuvo entre sus objetivos generar un cambio orientado a crear una cultura de servicio y excelencia que se reflejara en una mejor atención a la ciudadanía, así como una mayor productividad y beneficios en cuanto a la reducción de costos; esto es, instrumentar un programa de cambio que difundiera ampliamente los valores de calidad, servicio y excelencia en el trabajo que fomentara la eficiencia en los recursos y se implantara en la forma más eficaz posible. Es importante señalar que el Programa de Desregulación y Simplificación Administrativa (PDSA) proveyó de un marco legal institucional cuyos principios -que ya han sido explicados - favorecieron la realización de estos propósitos. De esta manera, el PCE buscó infundir la productividad, la calidad, el servicio y la excelencia como base de una nueva cultura, esto con base en un apoyo específico en áreas criticas consideradas de alto impacto.

En el estudio de caso se dirige el análisis desde las dos vertientes estratégicas (desregulación y calidad y excelencia). Las vertientes están entrelazadas y son estas dos vías estratégicas las que le dieron sentido integral al Programa como tal.

La finalidad fue atender las necesidades de los grupos de interés como la ciudadanía, los empleados y el gobierno, a través de procesos ágiles, una organización proactiva que incluyera la participación, la automotivación y la autoestima; así como el uso de recursos adecuados como tecnología avanzada en forma integral.

El CMA fue una pieza sustantiva del proceso. Como tal, fue la pieza organizacional que vinculó la filosofía general del PMA con la Delegación. De la misma manera el CMA fue el responsable de que el programa se desarrollara y cumpliera de acuerdo a los planes establecidos, ya que su función básica dentro de la Delegación fue la de ejecutar los proyectos y darle seguimiento a los mismos. El CMA, en Álvaro Obregón, reportaba al Coordinador de Asesores y al Subdelegado de Administración. 


\subsection{Historia del proceso de implementación}

A partir del mes de junio de 1995 el PCE inició en la Delegación con el objetivo de generar una cultura de servicio y excelencia que resultara en una mejor atención a la comunidad, mediante el apoyo a áreas criticas de alto impacto. El análisis y rediseño de los procesos se llevó a cabo mediante equipos multidisciplinarios que involucraban a personal de distintos niveles de la Delegación.

A raíz del diagnóstico inicial y selección de los procesos se escogieron cuatro procesos:

- Resolución de trámites.

- Atención a la demanda ciudadana.

- Mantenimiento urbano.

- Mantenimiento a edificios públicos.

La vía para implementar el PCE en la Delegación Álvaro Obregón estuvo compuesta por cuatro fases:

Diagnóstico y selección de los procesos críticos.

1) Evaluación y rediseño de procesos críticos.

2) Diseño de los procesos críticos.

3) Conversión de los procesos críticos.

La fase cuatro de la reingeniería de procesos (conversión de procesos críticos) se llevó a cabo en tres etapas:

1) Preparación y mejoras iniciales (septiembre a diciembre de 1995).

2) Implementación de nuevos procesos (enero a junio de 1996).

3) Consolidación y mejora continua (julio de 1996 a noviembre de 1997).

\subsection{Los actores organizacionales; internalización de los simbolos y nueva cultura organizacional}

Se pudieron identificar principalmente la existencia de un Comité Director compuesto por el Delegado, el Coordinador de Asesores, el Contralor Interno, los Subdelegados, el CMA y los líderes de los equipos de trabajo. El Delegado fue la cabeza del Comité y los Subdelegados fueron los responsables de coordinar cada proceso y equipos en tanto que las funciones del CMA fueron preparar, facilitar y documentar las sesiones de trabajo, asimilar y aplicar la metodología de reingeniería de procesos, y promover el PCE al tiempo que lograba su arraigo en todos los ámbitos de la Delegación.
Estas funciones se enfocaron a dar seguimiento a las solicitudes y propuestas de los equipos de rediseño presentadas al Comité Director, a elaborar el plan de implantación del PCE en coordinación con los equipos y a asegurar y evaluar la inplémentación de los proyectos generados. Como parte de la internalización de los valores de calidad y excelencia destacó la regularidad de las reuniones de trabajo en donde convivían funcionarios de distintas áreas y niveles.

La transformación cultural hacia una vocación dirigida a la atención al cliente enfrentó décadas de inercia donde los ciudadanos, al desconfiar de los servidores públicos, desarrollaron mecanismos que permitían la desviación irregular de los reglamentos para su beneficio. Esta actitud no ha cambiado, por lo que diversos servidores públicos encontraron difícil implementar principios organizacionales de confianza hacia el usuario. No existía un sistema de estímulos económicos y se identificó que al momento se conforman con ciertos incentivos simbólicos como el agradecimiento del ciudadano, la participación de altos mandos en el programa y el respaldo de la autoridades.

\subsection{Los mecanismos organizacionales; la institucionalización del cambio}

Un aspecto fundamental para la institucionalización del cambio fueron los cambios e innovaciones en el marco jurídico que regula el ejercicio de gobierno en el D.F. y en particular en las Delegaciones. De esta manera, existió un marco legal que al formular categorías como la afirmativa ficta y la buena fe, entre otros, alientó una actitud positiva hacia el ciudadano y obligó a la corrección constante de los procedimientos organizacionales para dar respuesta expedita al usuario. El Manual de Trámites y Servicios aseguró una base transparente para la relación ciudadano servidor público. Otro aspecto importante fue que el CMA estuviera incluido en la estructura delegacional.

Un eje operativo del proceso, desarrollado a través del PCE, fueron los grupos de trabajo en donde se reunían regularmente a personal de diferentes áreas de la Delegación y de diferentes niveles jerárquicos. Tenían sesiones periódicas de una hora en promedio. Una característica importante que se observó fue que las distancias jerárquicas se reducían en las sesiones, asimismo el liderazgo del grupo no recayó necesariamente en la jerarquía de mayor nivel sino que lo asumían aquellos con mayor conocimiento técnico del asunto a tratar.

Destaca el establecimiento de la imagen corporativa o institucional de la VUD, cuyo elemento central es el logotipo de todas las aplicaciones de éste en señalamientos, papelería, letreros, gafetes, promocionales, posters, y anuncios. De igual forma sobresale la ubicaciòn del CESAC en un lugar fijo y con características que lo distinguen de las demás áreas. Estos elementos permiten 
conservar las bases para un proceso de institucionalización, aunque se presentan algunos nudos en términos de la capacidad de inducción.

\section{Caso de Estudio. Delegación Venustiano Carranza}

\subsection{Modernización administrativa de la Delegación Venustiano Carranza: objetivos y elementos estratégicos}

Es importante señalar que, en el aspecto formal, el Programa de Modernización Administrativa aplicado en la Delegación Venustiano Carranza, en particular el Programa de Calidad y Excelencia (PCE) tuvo grandes similitudes con el del caso anterior. Esto es así porque la definición de los criterios generales emanan de la misma fuente (i. e. la Dirección General de Modemización Administrativa $y$, en un principio, la empresa consultora Arthur D. Little). Así pues, los cuatro procesos son los mismos, cuyos nombres originales para esta Delegación fueron: Control de Gestión, Ventanilla Única, Mantenimiento Urbano y Mantenimiento a Edificios Públicos ${ }^{10}$. En el caso que nos ocupa ahora, se debe señalar que a nivel delegacional se siguió identificando a los procesos con estos nombres.

Asimismo, el Programa de Desregulación y Simplificación Administrativa (PDSA) tuvo una incidencia en el desempeño general de la Delegación, pues, como se ha dicho, proveyó de un marco general cuyo enfoque facilitó centrarse en la atención al ciudadano.

Como en el caso de estudio anterior, fue a través de las dos vías estratégicas del PMA (desregulación y calidad y excelencia) que el análisis se desarrolla. La intención particular del Programa en esta Delegación fue integrar las iniciativas, inquietudes y necesidades de mejora en el personal, con una visión participativa, a través de grupos de trabajo de diversas áreas y niveles y buscando un sentido de pertenencia que coadyuvara a mejorar la actuación de la Delegación ante la ciudadanía.

\subsection{Historia del Proceso de Implementación. Cambios de autoridades}

El PCE en la Delegación Venustiano Carranza inició en el mes de enero de 1996 al integrar los equipos de trabajo corres- pondientes a los cuatro procesos seleccionados anteriormente, aun cuando en noviembre de 1995 ya se habían llevado a cabo reuniones ente la Delegación y la consultora $\mathrm{ADL}$.

De esta manera de enero al 16 de abril del mismo año, los equipos se reunían en sesiones de cuatro horas en promedio con la participación permanente de un representante de Oficialía Mayor y un coordinador de calidad de la Delegación y en reuniones quincenales con el Comité Director. En este mes se incorporó el Coordinador de Modernización Administrativa (CMA) a las sesiones de trabajo y desde entonces ha venido trabajando en la implantación del PCE. Finalmente en agosto de 1996 la empresa consultora se retiró de la Delegación quedando como responsable del programa el CMA.

Una vez identificados los procesos críticos el camino para implantar el PCE se compuso de cuatro fases: Diagnóstico y selección de procesos críticos, Evaluación y rediseño de procesos críticos, Diseño de procesos y Conversión de procesos críticos. Esta última fase se llevó a cabo en tres etapas: preparación y mejoras iniciales; implementación de nuevos procesos y consolidación y mejora continua.

Esta Delegación sufrió modificaciones en sus autoridades que de alguna forma impactaron en el proceso de implementación del PMA. Así, en septiembre de 1996 cambió el Subdelegado Administrativo por una persona ajena al programa. Esto propició, al principio, incertidumbre entre integrantes del Programa, que después disminuiría, con ligeras tensiones y distensiones.

Tres meses después cambió el Subdelegado de Participación Ciudadana, pero, a diferencia del anterior, el Coordinador de Control y Gestión, y líder de uno de los equipos, ascendió a esta Subdelegación. Estas modificaciones al principio produjeron conflicto pues el nuevo coordinador desconocía la labor que se realizaba en el proceso, después se sumó a la dinámica ya generada por el resto de los integrantes.

\subsection{Los actores organizacionales: internalización de los símbolos y nueva cultura organizacional}

Al igual que en el caso de estudio anterior, fue posible identificar un Comité Director compuesto por el Delegado, los Subdelegados, el CMA y los líderes de los equipos de trabajo. Asimismo, las reuniones de los equipos de trabajo se llevaban a cabo con normalidad. La funcionalidad de los grupos no dependía tanto de la posición jerárquica que ocupa el líder, sino en la participación colectiva.

El CMA cobró una dimensión muy particular en este caso. Diversos miembros de los equipos y autoridades de la Delegación coincidieron en señalar que su trabajo fue fundamental 
para la consolidación de los equipos de trabajo. Es importante destacar que el CMA guarda una muy buena relación de trabajo con el Delegado y quizá por ello los cambios en el área a la que está adscrito (la Subdelegación de Administración) no afectaron en demasía. La relación con los integrantes de los equipos de trabajo se basó sobre todo en el análisis técnico de los problemas de cada área y de cómo se pueden resolver con base en las herramientas del PMA o con recursos de la Delegación. Asimismo, destacó su capacidad de convocatoria para el trabajo igualmente técnico, en particular para la realización de indicadores de desempeño.

Con respecto a estos últimos, hay que resaltar que los integrantes de los equipos y algunas otras personas de sus áreas de trabajo trabajan en ellos de manera continua. Su metodología cumple con la estipulada por la Secretaria de la Controlaría y Desarrollo Administrativo, igual a la que la Contraloría General del D.D.F. exige se utilice para la entrega de indicadores.

\subsection{Los mecanismos organizacionales: la institucionalización del cambio}

La modificación del marco normativo fue también en este caso un importante factor de institucionalización del cambio. Las nuevas leyes y su filosofía propiciaron, complementaron y dieron sentido al trabajo de los grupos, en especial al de Ventanilla Única, pues esta área estuvo directamente vinculada al área central encargada del PDSA.

Al igual que en el caso de estudio anterior, la VUD de Venustiano Carranza cumplió con el Manual de Identidad Corporativa. Se ubicó en la entrada del edificio sede de la Delegación y por ello satisfizo la necesidad de que fuera fácilmente localizable. De la misma forma sobresale el establecimiento del CESAC con las mismas características que en Álvaro Obregón.

Además, una carảcterística muy importante en este caso de estudio fue el énfasis que se puso en la capacitación, sobre todo, de personal de base, pues este tipo de empleados permanecería en la estructura administrativa del D.D.F. con mucho mayor seguridad que los empleados de confianza. Muchos de los integrantes de los equipos de trabajo fueron personal de base que realizaban funciones operativas.

\section{Conclusiones}

Es importante recordar que el objetivo metodológico de la investigación se centró en realizar una evaluación parcial a través de dos estudios de caso. Las inferencias que se puedan ob- tener de una muestra de este tipo a través de la metodología no son factibles de generalizar. Sin embargo, dadas las capacidades comparativas de los casos escogidos es posible obtener importantes inferencias que den luz sobre lecciones posibles para experiencias de modernización similares.

Como se explica en la introducción de este trabajo y se justifica en el apéndice metodológico, la evaluación para obtener lecciones sobre el PMA se realizó en dos pasos: el primero es una comparación en términos de la congruencia entre los elementos generales del Programa y los instrumentados en las Delegaciones bajo estudio. Esta comparación permitió observar la congruencia y capacidad del PMA para inducir y generar los cambios planeados sobre las organizaciones que componen al D.D.F.

El segundo paso se llevó a cabo a través de la comparación de variables clave de cambio cultural e institucionalización del proceso de modernización entre los dos estudios. Ambos casos fueron considerados exitosos por los propios reformadores en términos de resultados y de capacidad de mejora continua y permanencia. Sin embargo, en un caso teníamos una situación "normal", es decir, el proceso de inducción en tal caso fue instrumentado desde el principio con estabilidad y constancia tanto por parte de las autoridades centrales del D.D.F. como por los funcionarios de la Delegación en cuestión (Álvaro Obregón). En el otro caso, teníamos una situación "de control" donde se realizaron cambios importantes de dirección y liderazgo en la Delegación durante el proceso de inducción y sin embargo el proceso de modernización no se vio afectado (Delegación Venustiano Carranza).

De esta manera al comparar estos casos entre sí, fue posible obtener un contraste en términos de las estrategias y los procesos que llevan al cambio cultural y a la permanencia y constancia de la nueva cultura organizacional (institucionalización). El estudio de la situación de "control" permitió vislumbrar más nítidamente los detalles clave o sustantivos, que, por contraste con el caso "normal", resaltaron como claros elementos críticos al proceso de modernización.

\subsection{Congruencia del PMA instrumentado en las Delegaciones}

Antes de comenzar con la comparación es importante recordar dos cosas sustantivas que fueron desarrolladas con mayor amplitud en la introducción del presente documento: primero, que la presente experiencia de modernización se encontró en una etapa temprana de institucionalización. Debemos recordar que el proceso de modernización comenzó en 1995, por lo que estamos estudiando un programa joven de modernización. Las comparaciones e interpretaciones que siguen toman en consi- 
deración de manera permanente este elemento. Segundo, y muy importante, este proceso de modernización se implementó en un contexto económico y político de alta complejidad y turbulencia debido a la grave crisis económica que estalló a finales de 1994 en México y a los profundos cambios político institucionales que el gobierno de la Ciudad de México experimentó, muchos de ellos sufridos justamente durante estos dos años que el PMA ha existido. No se estudió un programa de modemización implementado en situaciones "estables" sino bajo una presión política y económica de rápido cambio y emergencia respectivamente.

De la misma manera, es importante recordar que el presente análisis se enfocó básicamente al análisis del cambio de cultura organizacional y al proceso de institucionalización de las estructuras, mecanismos de trabajo y valores del PMA en las Delegaciones estudiadas. Otros elementos importantes como modificaciones estructurales o detalles respecto al incremento de la capacidad de respuesta gubemamental o reducción de costoś de operación, por ejemplo, no fueron analizados en esta investigación. La razón para esto, como se explicó en la introducción al documento, fue de orden metodológico derivado de las limitaciones de tiempo que existieron para desarrollar este estudio.

En términos genéricos, la línea estratégica de desregulación y simplificación administrativa impulsó toda una reforma legal y normativa del gobierno de la ciudad, otorgando herramientas sustantivas como la afirmativa ficta y la buena fe, marco que permitió, entre otras cosas, establecer un piso institucional para la mejora en la actitud y la capacidad de respuesta de los servidores públicos respecto a los ciudadanos.

Aunado a estos cambios legales y normativos sustantivos, la línea estratégica de calidad y excelencia, también en términos genéricos, promovió los mecanismos organizacionales para que el cambio de actitud hacia la calidad en la labor de los servidores públicos tuviera un referente comportamental e institucional. Entre muchos otros elementos, la incorporación de una Dirección de Calidad, apoyándose en Coordinadores de Reingeniería de Procesos en el sector Central y Desconcentrado, a la estructura de la Administración central de la ciudad fue un paso importante. La cuidadosa incorporación y selección de facilitadores para la inducción de las formas y mecanismos de trabajo en las demás áreas del D.D.F. generó el vínculo profesional y poco burocratizado entre los reformadores y los servidores públicos encargados del trabajo específico de cada organización. La inducción de la filosofía de calidad y excelencia a través de Coordinaciones de Modernización Administrativa (CMA) y de los Centros de Servicio y Atención Ciudadana (CESAC) desde dentro de cada Delegación (para el caso particular de este estudio) buscaron constantemente la incorporación de los principios del PMA, para que fueran esas instancias las que continuaran con sus propias particularidades, pero respetando los preceptos generales establecidos en las ocho vertientes, las acciones de modernización.
El análisis de los casos de estudio permitió observar lo siguiente:

1) El proceso de inducción del PMA y sus vertientes desde las autoridades centrales y de la Contraloría General del D.D.F. fue desarrollado de manera regular y sistemática, alcanzando impactos homogéneos y claros sobre las formas de actuación de las Delegaciones.

2) Tanto en Álvaro Obregón como en Venustiano Carranza, el marco normativo generado permitió la instrumentación del sistema de Ventanilla Única (VUD) con imagen corporativa conforme a la normatividad, homogénea y con ubicación acorde con fines. El trabajo de las VUD en ambas Delegaciones fue sistemático: se observó congruencia en términos de profesionalización del personal de las mismas, los manuales de información al usuario estuvieron disponibles en todo momento, el trabajo se desarrolló de manera constante y tuvo enlaces con las áreas responsables de dar respuesta a los trámites.

3) En ambas Delegaciones, los equipos de trabajo correspondientes a cada uno de los cuatro procesos clave a reformar, existieron y se reunían de manera sistemática. Existían relaciones cordiales con los facilitadores correspondientes. Los CMA y el CESAC operaron y cumplieron en términos generales con su labor. Existe un lenguaje que habla de las ocho vertientes y de los principios de confianza, afirmativa ficta, calidad y excelencia entre sus miembros, si bien las definiciones variaron de persona a persona, de equipo a equipo, y de institución a institución, el principio filosófico pareció más o menos común.

La conclusión en términos generales de este apartado es clara: se observó una congruencia muy alta entre los valores y propósitos del PMA y las condiciones generales a través de las cuales las Delegaciones implementaron y desarrollaron su propio proceso de modernización. Es plausible pensar que existian algunas variables clave para que este proceso haya tenido congruencia:

1) Existió una clara instrumentación que vinculó mecanismos tanto legales como organizacionales para alcanzar los objetivos. Es decir, hubo congruencia en la filosofía que desarrolla la transformación del marco legal (un gobierno que facilite las actividades de los particulares) y la transformación organizacional (principios de calidad y excelencia para mejorar el servicio a los clientes [ciudadanos] contando con servidores públicos motivados, participantes y profesionales).

2) Ambas líneas estratégicas de acción se preocuparon desde el inicio del proceso por generar cambios pero aunado a mecanismos institucionales precisos que permitían la permanencia y mejora de las acciones y filosofia del PMA. La incorporación de principios legales que genera- 
ron comportamientos precisos de los servidores públicos (como buena fe y afirmativa ficta) tuvieron un claro impacto en la institucionalización del proceso. La incorporación de estructuras formales de enlace y en las propias Delegaciones para la instrumentación de principios de excelencia y calidad fueron otro claro aspecto que probó la permanente preocupación por hacer de este PMA un programa que alcanzara institucionalización también de abajo arriba. Los facilitadores, los CMA y los CESAC fueron espacios organizacionales que buscaron desde su origen transferir la capacidad y responsabilidad del proceso de modernización a la propia gente de las Delegaciones. Es importante observar, sin embargo, que esta estrategia de institucionalización corre el riesgo de hacer dispersa la filosofía inicial del PMA. Como se observó anteriormente, muchos principios y definiciones del proceso de modernización son heterogéneos. Esto se debió en una buena parte a la capacidad de adaptación de los agentes organizacionales que enfrentaron situaciones particulares y específicas a su Delegación. El PMA tomó este riesgo como necesario, debido a que es congruente con la filosofía del programa descentralizar sus actividades y hacer que éstas fueran incorporadas realmente por los servidores públicos. Este riesgo buscó ser minimizado a través del marco legal congruente y claro, y a través de una relación y seguimiento estrechos entre las autoridades centrales y los encargados del programa (CMA y CESAC entre los principales). Este punto fue, sin embargo, un punto problemático que ahondaremos en la última sección de estas conclusiones.

3) El apoyo que el PMA y sus estrategias recibieron de las autoridades máximas del D.D.F. fue definitivamente una clave para entender la posibilidad y facilidad de acceso de los mecanismos de inducción desde la Dirección General de Modernización Administrativa a las Delegaciones, sus dirigentes y los propios servidores públicos. Esto permitió que la influencia y la capacidad de alcanzar mejores acuerdos y voluntad para el desarrollo de los mecanismos de cambio se generen a un alto nivel de congruencia.

4) Las etapas del proceso de inducción fueron llevadas con rapidez pero con sensibilidad ante las diferentes situaciones particulares encontradas en diferentes organizaciones del D.D.F. Al estar analizando un proceso que claramente no ha terminado, se pueden observar al menos tres etapas en el proceso: rompimiento, inducción e institucionalización (cuadro 3) ${ }^{11}$. Las ideas y filosofias del programa tenían (y todavía tienen) que enfrentar resistencias al cambio a diferentes niveles jerárquicos en algunas organizaciones dentro del D.D.F. Las inercias y costumbres de organizaciones tan grandes como el
D.D.F. obligaron a desarrollar importantes esfuerzos iniciales con el fin de convencer y generar las bases para inducir un cambio. En esta etapa se desarrollaron importantes transformaciones legales y normativas que pusieron una base sólida para generar el cambio. En la etapa de inducción, los constantes esfuerzos de convencimiento y de búsqueda de mecanismos para impulsar los principios de calidad. y. excelencia en las Delegaciones implicaron un alto nivel de imaginación y creatividad (facilitadores, pláticas con CMA y los miembros de los equipos, cursos de capacitación, entre otros). De la misma manera, la consolidación de diversos principios legales en la generación y homogeneización de las VUD fueron procesos sustantivos para que la inducción del proceso tuviera un espacio organizacional concreto, obligatorio e institucional. La etapa de institucionalización, es donde creemos que de manera básica se encuentra hoy día el proceso al menos en estas dos Delegaciones, ha implicado un esfuerzo constante de reflexión al enfrentar nuevos retos. Algunos de estos retos los hemos descrito ya: las dificultades para incorporar mejores mecanismos de medición de resultados, la diversidad en términos de comprensión e implementación de diversos principios filosóficos del programa por parte de los servidores públicos de las Delegaciones, los diversos tiempos y retos para conformar el CESAC o para elegir al CMA de manera óptima y las situaciones que trae consigo el término de un período administrativo.

\section{Comparación entre los dos casos}

Es conveniente recordar que el análisis comparativo desarrollado aquí tiene una relación fundamental con el proceso de inducción diseñado e impulsado por las autoridades centrales del D.D.F. En este sentido, el análisis comparativo que sigue tomó en consideración que el elemento central que se evalúa en términos de cambio cultural y proceso de institucionalización estuvo permanentemente vinculado a las estrategias de inducción antes referidas.

\subsubsection{Comparación en términos de cambio cultural}

\section{Similitudes:}

1) De manera específica, el PMA definió cuatro procesos clave a rediseñar, lo que permitió que los equipos instrumentados en cada área de cada Delegación se ocuparan de los mismos problemas y prioridades.

2) El siguiente elemento que salta a la vista fue que los conceptos y definiciones de las categorías legales y de 


\begin{tabular}{|c|c|c|}
\hline Etapas & Problemas & Estrategia-dilemas \\
\hline Rompimiento & $\begin{array}{l}\text { - Convencimiento de actores clave. } \\
\text { - Consenso entre los actores clave de la } \\
\text { modemización. } \\
\text { - Resistencias de ciertos actores, estrategias de } \\
\text { confrontación, estrategias de simulación. }\end{array}$ & $\begin{array}{l}\text { - Negociación o imposición. } \\
\text { - Acuerdo técnico o acuerdo político. ¿Cuál es el } \\
\text { - } \text { más efectivo? } \\
\text { Negociación, seguimiento, institucionalización } \\
\text { temprana ¿Cómo identificar la simulación? }\end{array}$ \\
\hline Inducción & $\begin{array}{l}\text { - Reglas de acercamiento y consolidación. } \\
\text { - Valores y principios de homogeneidad e } \\
\text { interpretación. } \\
\text { - Actores organizacionales generan nuevos valores. } \\
\text { - Principios ¿Son congruentes? }\end{array}$ & $\begin{array}{l}\text { - Congruencia de marcos nomativos generando } \\
\text { incentivos adecuados y efectivos. } \\
\text { - ¿Hasta dónde homogeneidad, hasta dónde inducción } \\
\text { de los valores? } \\
\text { - Cómo lograr que los nuevos valores sean congruentes? } \\
\text { - Claridad de o impulso de la autonomía. }\end{array}$ \\
\hline Institucionalización & $\begin{array}{l}\text { - Consenso/imposición de valores. } \\
\text { - Reglas y espacios organizacionales establecidos, } \\
\text { aceptados y operativos. } \\
\text { - Equilibrio Autonomía/Congruencia. }\end{array}$ & $\begin{array}{l}\text { - ¿Hasta dónde la imposición de parámetros establecidos? } \\
\text { - Impulso a la estabilidad. } \\
\text { - Operación de menos estructuras. } \\
\text { - Mecanismos organizacionales. } \\
\text { - Nuevos actores con nuevas dinámicas. } \\
\text { - ¿Cómo generar autonomía, pero con valores } \\
\text { congruentes con la idea de modernización? }\end{array}$ \\
\hline
\end{tabular}

calidad y excelencia entre los miembros de los equipos, en ambas Delegaciones, fueron heterogéneos.

3) Los equipos de trabajo tuvieron muy diferentes grados de maduración en ambas Delegaciones.

4) Los equipos de trabajo en ambas Delegaciones desarrollaron diferentes prioridades respecto a la necesidad de impulsar indicadores de desempeño y efectividad profundos y sistemáticos.

En resumen, la gran similitud en este punto respecto a los dos casos fue la gran heterogeneidad que se encontró en el tipo, estructura, filosofía y capacidad de los equipos de rediseño. Es de destacar que una estrategia que impulsa una filosofia de calidad y excelencia acepta de partida la necesidad de descentralizar los esfuerzos y las estructuras organizacionales. Aun cuando las estrategias de inducción estuvieran apoyadas en marcos legales innovadores y en estructuras facilitadores del cambio organizacional, es de esperar que en la etapa de inducción e institucionalización en organizaciones grandes y complejas como el D.D.F. un importante nivel de heterogeneidad en los equipos semiautónomos de trabajo. Es en este punto que una variedad de elementos organizacionales comienzan a afectar un proceso de modernización de esta envergadura: estilos de liderazgo, grupos y relaciones políticas intra e interorganizacionales, mecanismos de resistencia de diversos actores organizacionales ante cálculos administrativos o políticos coyunturales, etc. (cuadro 4).

\begin{tabular}{|c|c|c|}
\hline & Conjunción de Conceptos & CMA y Equipos de Trabajo \\
\hline Aluaro Obregón & $\begin{array}{l}\text { - Reducida conjunción entre definición, no sólo con } \\
\text { PMA sino también entre distintos equipos y del } \\
\text { mismo grupo. }\end{array}$ & $\begin{array}{l}\text { - CMA: Alto nivel de compromiso. Cauteloso y } \\
\text { observador. Reducido esfuerzo por sistematizar } \\
\text { indicadores de desempeño. } \\
\text { - Equipo de trabajo: Heterogéneos. } \\
\text { - Resultados: Algunos equipos participativos y } \\
\text { constantes. Otros más disniriñ y y iarticulados. } \\
\text { El liderazgo de los equipos varia, en uno o más } \\
\text { participativo; en otros más autoritario. }\end{array}$ \\
\hline Venustiano Carranza & $\begin{array}{l}\text { - Reducida congruencia entre definición no sólo con } \\
\text { PMA sino entre miembros de distintos equipos y del } \\
\text { mismo grupo. }\end{array}$ & 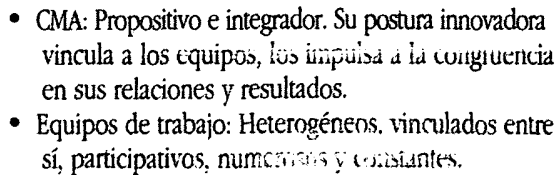 \\
\hline
\end{tabular}




\section{Diferencias:}

1) Las características de liderazgo y compromiso de los actores principales como el CMA de cada Delegación fue particularmente diferente. En una (Álvaro Obregón AO) se tuvo un liderazgo cauteloso, conservador y comprometido institucionalmente. En Venustiano Carranza (VC) sin embargo encontramos un estilo muy diferente, propositivo, innovador y altamente dinámico.

2) La descentralización de las decisiones de las instancias superiores a los equipos fue variable. Un alto nivel de descentralización y comunicación inter-equipos (al grado que los dos de mantenimiento trabajaron en forma conjunta) se encontró en VC. Mayor formalidad y relaciones más ligadas a jerarquías y posiciones organizacionales se encontró en $\mathrm{AO}$.

3) La necesidad sentida de los equipos por definir y sistematizar indicadores de desempeño como una forma de consolidar el trabajo y los resultados de los equipos fue más clara (debido a insistentes esfuerzos del CMA) en $\mathrm{VC}$. En $\mathrm{AO}$, este proceso todavía fue lento ya que existieron claras resistencias de diversos niveles para avanzar con mayor rapidez en este sentido.

4) La visión de capacitar e involucrar en los equipos de trabajo a personal de base fue prioritaria en Venustiano Carranza, mientras que en $\mathrm{AO}$ los integrantes de los equipos fueron en su mayoría mandos medios de la Delegación, además en VC los secretarios particulares de los Subdelegados y del Delegado participaron en los equipos de trabajo.

5) Es importante recordar que Álvaro Obregón (junto con Azcapotzalco) fue la Delegación donde se puso en marcha el PMA de manera piloto.

En resumen, la diferencia general que se encontró en términos de cambio organizacional al comparar los casos parece tener una relación importante con la heterogeneidad encontrada en el punto anterior. Los equipos de reingeniería fueron sumamente heterogéneos, siendo esto causa y a la vez efecto de las diferentes culturas organizacionales y estilos de liderazgo que se encontraron en cada espacio de las Delegaciones. Diferentes valores al ser inducidos desde el PMA son interpretados y definidos con cierto nivel de discrecionalidad que ningún mecanismo de institucionalización pudiera reducir a cero. Esto es, pareciera plausible establecer que una estrategia de modernización que desea inducir en una organización compleja principios de atención a las necesidades de los particulares, calidad, y excelencia, al descentralizar la toma de decisiones como prerrequisito, debe aceptar perder cierto nivel de control sobre el proceso. Esta pérdida de control relativa se reflejará precisamente en la diversidad y heterogeneidad de principios y por lo tanto de estructu- ras y sentidos reales de comportamiento de los agentes organizacionales. Dos preguntas clave aparecen aquí: cqué tanto los mecanismos legales y filosofias organizacionales inducidas pueden dirigir a esta discrecionalidad o pérdida de control a un nivel aceptable de tal manera que no afecte la congruencia del programa como un todo? y por lo tanto ¿cuál es el nivel aadecuado 0 aceptable de esta pérdida de control o heterogeneidad de valores, estilos y estructuras de comportamiento? Estas preguntas son muy importantes, no sólo en el momento de rompimiento e inducción, sino también en la etapa de institucionalización. El incentivo para intentar eliminar las diferencias de estilo y comportamiento con el afán de hacer congruentes las actividades del Programa puede generar más resistencias y diversos comportamientos de simulación por parte de los actores de cada Delegación. Pero un nivel muy alto de heterogeneidad puede amenazar la posibilidad y capacidad de continuación del Programa y süs efectos. Particularmente en esta etapa de institucionalizacion, es importante analizar el equilibrio que parece necesario entre inducción, mecanismos legales y estructurales para generar homogeneidad de valores, y la necesaria e inevitable (hasta cierto punto) heterogeneidad de capacidades y estilos de liderazgo.

\subsubsection{Comparación en términos de mecanismos organizacionales de institucionalización}

\section{Similitudes:}

1) Se ha hablado de la heterogeneidad de los equipos de trabajo en términos de valores, estructuras y filosofías. En este punto nos referimos al mismo fenómeno pero como problema de mecanismos organizacionales de institucionalización. El papel del CMA en cada equipo de trabajo y el del liderazgo personal del responsable del equipo parecen factores clave. Ambos casos fueron similares en términos de la todavía reducida capacidad que se observó de los equipos para obtener un alto nivel de autonomía respecto a las dinámicas propias de otros niveles jerárquicos de la Delegación.

2) Los otros espacios organizacionales sustantivos del proceso de modernización (CMA, CESAC y VUD) fueron operativos, están constituidos y trabajan sistemáticamente en ambos casos bajo las normas y filosofía del PMA en general, aunque existen diferencias a nivel particular.

3) Los criterios que reformaron el marco legal y normativo del D.D.F. tuvieron un impacto altamente positivo para inducir las reglas y normas de comportamiento general en los espacios organizacionales (sobre todo VUD y a 
partir de ahí a las áreas dictaminadoras y equipos de trabajo) en ambas Delegaciones.

4) La filosofía inducida de calidad y excelencia generó espacios organizacionales concretos en ambas Delegaciones que se comportaron en lo general bajo los principios de atención al cliente y excelencia en el trabajo compartiendo la idea de que es sustantiva la participación de los servidores públicos para alcanzar resultados.

5) En ambas Delegaciones existió la apreciación de la necesidad de desarrollar un sistema más amplio de información de gestión, no sólo como parte de un sistema de atención a clientes, sino como de gestión integral (control de gestión).
En síntesis, los mecanismos urganizacionales pensauus desde el PMA para institucionalizar el programa se cristalizaron en equipos de trabajo, estructuras organizacionales y patrones de comportamiento dentro de las Delegaciones. Sin embargo, como en todo proceso de institucionalización, hubo dificultades para generar liderazgos participativos, y reducida capacidad de autogestión tanto en las estructuras formales como en los equipos de trabajo son todavía identificables. A partir de las similitudes, se pudo observar que los espacios y las reglas de institucionalización están dadas y parecen sólidas, sin que todavía se pueda asegurar que los agentes a nivel individual, o los equipos a nivel general tengan capacidad de generar con suficiente fuerza una dinámica de autogestión que hiciera "automática" la forma particular de trabajo y los principios de modernización inducidos (cuadro 5).

\begin{tabular}{|c|c|c|c|c|c|}
\hline \multicolumn{6}{|c|}{ 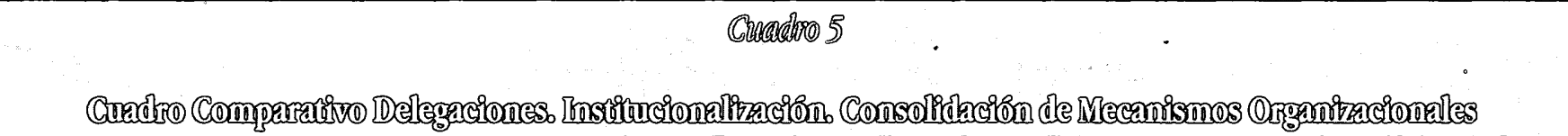 } \\
\hline & CMA & CESAC & VUD & Equipos & Indicadores \\
\hline Alvaro Obregon & $\begin{array}{l}\text { - Constituido, constante. } \\
\text { - Conservador y preca- } \\
\text { vido. }\end{array}$ & - Constituido y constante. & $\begin{array}{l}\text { - Conflictos para sostener } \\
\text { el equipo de Ventanilla } \\
\text { única, diversos cambios } \\
\text { y problemas. } \\
\text { - Constituido } \\
\text { - Implementando sistemas } \\
\text { de información aunque } \\
\text { con restricciones. } \\
\text { - Identidad corporativa: } \\
\text { Excelente. }\end{array}$ & $\begin{array}{l}\text { - Heterogéneos. } \\
\text { - Algunos no son total- } \\
\text { mente constantes. } \\
\text { Dependen mucho del } \\
\text { CMA y del estilo de li- } \\
\text { derazgo de cada grupo. }\end{array}$ & $\begin{array}{l}\text { - Retraso a su } \\
\text { implementación. } \\
\text { - Difícil conocer } \\
\text { resultados reales y } \\
\text { profundos. } \\
\text { - Resistencias a } \\
\text { desarrollarlos. }\end{array}$ \\
\hline Venustiano Carrranza & $\begin{array}{l}\text { - Constituido constante. } \\
\text { - Altamente innovador } \\
\text { y activo. }\end{array}$ & $\begin{array}{l}\text { - Constituido y constante. } \\
\text { - Innovadoras ideas dife- } \\
\text { rentes al PMA como } \\
\text { Control de Gestión o } \\
\text { Sistema Integral de } \\
\text { Información. }\end{array}$ & $\begin{array}{l}\text { - Constituidos y estables. } \\
\text { - Implementando siste- } \\
\text { mas de información. } \\
\text { - Identidad corporativa: } \\
\text { Excelente. }\end{array}$ & $\begin{array}{l}\text { - Heterogéneos. } \\
\text { - Trabajan con mayor } \\
\text { interrelación gracias al } \\
\text { CMA. } \\
\text { - Vinculados entre sí. } \\
\text { - Algunos son constantes. }\end{array}$ & $\begin{array}{l}\text { - Avance significativo. } \\
\text { - Se están dando las } \\
\text { condiciones para que } \\
\text { estos indicadores y el } \\
\text { sistema que los genere } \\
\text { sean más profundos y } \\
\text { permanentes. }\end{array}$ \\
\hline
\end{tabular}

\section{Diferencias:}

1) La estabilidad de las estructuras. Si bien es en VC donde se generaron cambios de los altos mandos de la Delegación, el CMA fue una persona que logró estabilidad en el puesto. Esto permitió en parte observar la estabilidad de las estructuras y personas que las dirigen en los equipos. En AO, curiosamente, la estabilidad en algunos equipos fue más difícil, aun cuando el CMA fue estable así como las altas autoridades de la Delegación.

2) La preocupación por la institucionalización de las formas y mecanismos que el PMA impulsaron se observa más nítidamente en $\mathrm{VC}$ que $\mathrm{AO}$.

3) En AO existió un proceso más largo de inducción y experiencia en los equipos que en VC lo que permitió ob- servar un nivel mayor de conciencia de los obstáculos y posibilidades de ciertos proyectos.

En otras palabras, las diferencias señalaron que la inestabilidad generada por los cambios en las estructuras de mando en las Delegaciones pudiera ser minimizada gracias a los esfuerzos sistemáticos de institucionalización generados desde las dos líneas estratégicas de acción (desregulación y calidad y excelencia). Sin embargo, muestran como crítico el proceso de designación y mantenimiento de relaciones con personajes clave como el CMA. Al menos en términos de la etapa de institucionalización, la estabilidad y constante comunicación y relación con el CMA, es decir, con la última instancia de vinculación del programa con los servidores públicos, aparece como una variable crítica. Su estilo de liderazgo, tipo de compromisos, habilidades y posición dentro de la organización, con el Delegado, facilitadores y autoridades centrales fueron decisio- 
nes fundamentales para dirigir exitosamente un proceso de inducción como este.

\subsection{Consideraciones finales: lecciones para experiencias de modernización similares}

\subsubsection{El contexto particular}

Todo proceso de modernización que involucra una organización gubernamental de la envergadura e importancia del D.D.F. implica una serie de variables complejas a nivel contextual que no pueden ser "controladas" o soslayadas metodológicamente.

\subsubsection{Crisis económica y turbulencia política}

La primera cuestión ya ha sido desarrollada en la introducción al documento, pero es fundamental repetirlo aquí: la severa crisis económica y la rápida y turbulenta transición política que se vivió en México desde finales de 1994 y que expresaron en la ciudad de México potenciadas a su máximo nivel. Ésta fue una cuestión clave para entender la presente experiencia de modernización, tanto en términos de sus severos límites impuestos por el contexto, como por algunas ventajas (aunque en menor medida) que estos mismos procesos implicaron. Restricción severa de recursos que se destinan al proceso de modernización y alto nivel de sensibilidad política de la sociedad han sido importantes factores que han frenado y algunas veces impulsado al propio proceso.

\subsubsection{Amplia participación y apoyo de máximas autoridades del D.D.F.}

Ésta fue una cuestión sustantiva: sin el apoyo definitivo y total de las altas autoridades del D.D.F., el impacto y capacidad de este programa de modernización hubiera sido significativamente menor. La prioridad estratégica que el equipo de modernización dio a desarrollar y alimentar este apoyo fue fundamental.

\subsubsection{Relaciones con el Sindicato}

Ante la restricción económica severa del país, la posibilidad de impulsar el programa vía incentivos económicos fue prácticamente nula. Por la misma razón, existió la dificultad intrínseca de generar un programa de modernización que no tuviera como principio la reducción de personal. El proceso de modernización se vio aliviado de una pesada carga al definir un programa que mejoraría la actuación del D.D.F. sin requerir el despido de personal sindicalizado.

\subsubsection{Proceso de modernización en diferentes etapas, cada una con diferentes dinámicas y estratégicas}

En este documento se ha propuesto entender al proceso de modernización administrativa como uno dividido en tres etapas dinámicas y complejas: rompimiento, inducción e institucionalización (cuadro 3). Cada etapa del proceso, como procesos complejos a su vez llevan a un programa de modernización a enfrentar varios dilemas. En general, podemos establecer que el dilema básico está en que un proceso de modernización que busca generar organizaciones autónomas, responsables, con valores precisos de atención al cliente y efectividad, requirió establecer un proceso cie descentralización en la toma de decisiones hacia las diversas partes organizacionales. Qué tan rápido y cómo se realice esta descentralización aparecen como elementos clave. Una descentralización muy rápida puede generar anarquía en los espacios organizacionales más autónomos, pero persiguiendo valores heterogéneos o distintos (y hasta antagónicos) a los que inspiraron el proceso de modernización. Una descentralización muy lenta puede implicar que los actores organizacionales, aquellos que actúan enfrentando a los clientes y a los problemas particulares pueden resistirse sistemáticamente a la inducción de valores, ya sea a través del boicot o más finamente a través de la simulación. La simulación es una de las formas más extendidas de resistencia organizacional, cuando los actores son cápaces de adaptar los valores y estructuras para mantener ciertos patrones comportamentales que incluso sean contrarios a los valores del programa modernizador. Como se aprecia en el cuadro mencionado, cada etapa tiene diversos dilemas y estrategias particulares. Un programa modernizador debe estar preparado para enfrentar estos cambios y diversos procesos por los cuales una transformación organizacional avanza. En la etapa de rompimiento, por ejemplo, un programa modernizador debe estar preparado para equilibrar la negociación y el consenso con la fuerza para impulsar sus valores a través del convencimiento y la formalización legal y organizacional, como fue realizado en el PMA. La identificación de la necesaria institucionalización desde esta etapa parece ser clave. Es decir, como el PMA lo muestra, la preocupación por la institucionalización de programa en un lapso de tiempo determinado debe formar parte de la estrategia de rompimiento. En cambio, en la etapa de inducción, la combinación de principios legales de avanzada que generen incentivos claros al comportamiento eficiente, con las generación de espacios organizacionales que permitan ese comportamiento eficiente, aparecen como el gran reto. Surgen dilemas tales como hasta dónde homogeneizar valores y comportamiento y hasta dónde permitir y apoyarse en los valores que desde 
los nuevos mecanismos organizacionales (más autónomos y dinámicos que antes) generan en una dinámica propia. En la etapa de institucionalización este dilema entre homogeneidad de valores o mayor autonomía (o mejor dicho, la busca de su equilibrio) enfrenta los dilemas de las dos etapas anteriores (pues estas etapas no son cortes perfectos sino que más bien se traslapan ante la diversidad de espacios organizacionales con los que el gobierno de una metrópoli cuenta), resistencias y heterogeneidad de valores y mecanismos organizacionales. Y los enfrenta con el reto de hacerlos permanentes, naturales a la dinámica de los actores y de las organizaciones. El impulso a la estabilidad de los valores y las formas organizacionales nuevas, pero con la sensibilidad para aprender y desarrollar nuevos mecanismos a través de la autonomia relativa de las organizaciones que se mueven abora bajo patrones más libres y sustentados en la participación de los propios agentes, aparece como una estrategia clave en este espacio. Como lo muestra el PMA, justo en esta etapa de institucionalización en varios espacios del D.D.F., el alcance de este equilibrio no es sencillo y requiere tiempo y atención sustantiva a la dirección de los nuevos valores para generar su permanencia institucional.

\subsubsection{El dilema facultación de decisiones y congruencia del programa en las diversas partes de las organizaciones}

Un programa de modernización que, como el PMA, buscó generar una dinámica de los servidores públicos dirigida a la eficiencia y a la responsabilidad hacia los clientes o ciudadanos, confió en la expansión a través de la inducción, de nuevos valores organizacionales. Estos valores, que en el caso del PMA además encontraron un apoyo sustantivo y esencial en un nuevo marco jurídico innovador, tuvieron que ver con palabras como responsabilidad, descentralización, autonomía y capacidad organizacional y de sus actores para generar sus propias soluciones innovadoras a sus problemas cotidianos. Sin embargo, esta descentralización, esta búsqueda de autonomía y capacidad de las diversas organizaciones, implicó que en el proceso de cambio, de institucionalización, las nuevas organizaciones en realidad fueran más autónomas y pudieran generar valores nuevos y criterios alternativos a los del programa original. Estos criterios pudieran llegar a ser incluso muy diferentes o implicar nuevos mecanismos que el programa original no contempló en su momento. Hasta dónde estos nuevos valores generados impulsan un proceso congruente con la dinámica original no es algo automáticamente identificable. La búsqueda del equilibrio en este dilema es sustantivo: hasta dónde la homogeneidad de valores, hasta dónde ésto es congruente con la búsqueda de autonomía y participación. Hasta dónde la beterogeneidad es un simbolo de resistencia al cambio y simulación por parte de los agentes organizacionales, y basta dónde un sintoma de la forma en que los valores del programa de modernización ba tenido éxito en generar organizaciones más capaces, autónomas y responsables.

\subsubsection{La importancia de vincular tecnologías administrativas con marcos legales innovadores}

El PMA es un caso sumamente aleccionador de la importancia de que un programa modernizador encuentre su base y apoyo en un marco legal innovador, que no sólo sea congruente con los cambios organizacionales que se buscan, sino que además sea capaz de generar los incentivos institucionales para que el comportamiento eficiente y responsable se genere. En el PMA como se vio, el principio filosófico de un gobierno que coadyuva a la actividad de los particulares permitió la generación de principios normativos como la buena fe y la afirmativa ficta. Estos principios tuvieron implicaciones concretas en el comportamiento de los actores organizacionales y permitieron además la generación de nuevos reglamentos o normas que clarificaran y transparentaran las labores de los servidores públicos respecto a los ciudadanos.

\subsubsection{Inducción: basta cuándo, basta dónde}

Un programa de modernización en gobiernos metropolitanos es a final de cuentas un gran proceso de inducción de patrones valorativos y normativos dirigidos a múltiples organizaciones que componen el gobierno de una ciudad. Cada una de estas organizaciones, sin embargo, tienen sus propios actores organizacionales, actúan en un contexto particular y se enfrentan a problemáticas específicas. Un proceso de inducción puede aspirar a cierto nivel de homogeneización de los valores y los principios de actuación organizacional, sin embargo debe esperar cierta divergencia lógica. En todo caso, aspira a un equilibrio entre la flexibilidad de las formas de actuación reales (necesarias para enfrentar realidades concretas) y la congruencia con los valores y mecanismos organizacionales establecidos. En un programa, como en el PMA, además se tiene un reto adicional: se busca que las organizaciones generen espacios participativos e impulsores de la innovación de los actores organizacionales. Esto genera definitivamente organizaciones más autónomas y con capacidad de autogestión, que puede traducirse en la creación de nuevos valores por parte de tales organizaciones. Estos valores pueden ser más o menos congruentes con los inicialmente impulsados. La búsqueda de esta congruencia se convierte en un rol clave de cualquier programa modernizador. En el caso del PMA, esta congruencia ha sido buscada cuidadosamente desde el principio. Habría que añadir el programa de capacitación que este PMA ha desarrollado, a todos los niveles, 
con el fin de incrementar la probabilidad de que los valores generados por los actores organizacionales sean congruentes con los expresados por el programa.

\subsubsection{Tecnología}

Para que un programa de modernización tenga buenos resultados es importante el uso de la más avanzada tecnología. En el caso del PMA desde el inicio existió la preocupación de vincular adelantos tecnológicos y una infraestructura técnica adecuada, principalmente en aquellos espacios que tenían una relación más directa con la ciudadanía.

\subsubsection{Incentivos y recompensas}

Es importante que un programa de modernización revalore y dignifique a sus servidores públicos a través de incentivos como los reconocimientos, diplomas de participación, ceremonias y presentación de avances. Esto es, que si bien se trabajó con recursos limitados, en muchas ocasiones incentivos de carácter simbólico suelen ser útiles para. la puesta en práctica de un programa de modernización.

\subsubsection{La inducción de patrones de autonomia o autogestión}

El PMA muestra un interesante ejemplo de las ventajas y dificultades de una estrategia de modernización que enfatiza como sustantivo el lograr que las organizaciones que componen al gobierno de una ciudad tengan capacidad de respuesta adecuada a problemas complejos, vía la fortaleza de sus principios, de sus normas, de sus estructuras y sobre todo de la participación de sus miembros. En otras palabras, la búsqueda de un gobierno compuesto de organizaciones eficientes, responsables, parte de un diagnóstico que pone a los servidores públicos como pieza sustantiva de cualquier proceso de modernización. Es decir, servidores públicos capaces de responder a diversos problemas de la ciudadanía con rapidez y responsabilidad, en organizaciones con un alto nivel de autonomía ${ }^{12}$ y capacidad de autogestión. Inducir la capacidad organizacional para ser efectivo y eficiente para resolver los problemas de la ciudadanía, a partir de la generación de organizaciones con suficiente capacidad, es decir, con capacidad humana y técnica para resolverlos, no es un proceso libre de contradicciones. Tiempo y flexibilidad en las estrategias de inducción aparecen como una necesidad para alcanzar el éxito global del proceso de modernización. El proceso de institucionalización de estos valores para crear este tipo de organizaciones requerirán de un compromiso continuado y sistemático.
Ante los graves problemas que enfrentan las grandes metrópolis, pareciera una necesidad encontrar alternativas de cambio que sean capaces de generar en un lapso corto de tiempo resultados. Resultados que además satisfagan a una gran cantidad de actores. Sin embargo, si bien es posible hacerlo, como lo muestra el PMA que se ha analizado, también queda claro que los procesos de rompimiento, inducción e institucionalización requieren de continuidad en el compromiso y capacidad para sistematizar las experiencias, positivas y negativas, con el fin de adaptarla a las situaciones.

El PMA del D.D.F. se encontró en esta etapa de institucionalización con prometedores resultados preliminares. Existe un marco normativo innovador y congruentè con una metrópoli moderna de ciudadanos. Existen los mecanismos organizacionales con valores compartidos de eficiencia y atención al cliente. Se generaron los espacios y los procedimientos que, a través de la participación de los servidores públicos, fomenten la atención de primer nivel y el respeto a los ciudadanos. Lo más importante, tal vez, es que este PMA demostró que se puede cambiar a gigantescos conglomerados organizacionales en corto tiempo, o por lo menos establecer los principios normativos y organizacionales de este cambio con amplias probabilidades de institucionalizarse.

\section{Marco metodológico. Evaluación del Programa de Modernización del D.D.F.}

\section{Elementos básicos}

El objetivo de esta investigación fue formular un juicio analítico respecto a los resultados y perspectivas del Programa de Modernización del D.D.F.

Dadas las características del propio programa, la presente metodología guarda una serie de particularidades que es conveniente hacer explícitas:

1) El programa como tal tiene escasos dos años de existencia, lo que hizo complicado realizar una evaluación general debido sustantivamente a que difícilmente podrá hablarse de madurez o plena institucionalización organizacional y comportamental (en términos de los estudios longitudinales realizados por PeTTIGRew, 1979 y aun en términos de estudios con muestras amplias como los del grupo Aston (Pugh y Hickson, 1976). 
2) Las autoridaues actuales del D.D.F. se encontraban en el último año de un proceso sui generis tanto en términos administrativos (ésta fue una administración de tres años a diferencia de otras que tuvieron seis años) como en términos políticos (por primera vez en la era contemporánea los ciudadanos del D.F. eligieron al Jefe del Gobierno del D.D.F.). En términos metodológicos, estas condiciones sui generis evitaron realizar comparaciones con pasados esfuerzos y alertaron a los investigadores sobre las variaciones de comportamiento y discurso de los actores del programa que necesariamente fueron afectados por tales dinámicas. En este sentido, el juicio a realizar debió tomar en cuenta estas condiciones contextuales como sumamente importantes para la comprensión de las particularidades del comportamiento de los actores involucrados (en términos de los preceptos de validez para las interpretaciones expuestas en $\mathrm{HIsCH}$, 1967).

3) La evaluación debió ser realizada en sólo 5 meses, dadas tales condiciones especiales. Esto implicó que difícilmente se pudiera realizar una evaluación completa del programa en términos de todas las organizaciones involucradas en el proceso de cambio (sector, central, sector desconcentrado y procesos globalizadores o integrales). Fue necesario tomar una decisión en términos de simplificación del estudio y de justificación de la relevancia o representatividad derivada de la estrategia de investigación (bajo los criterios mínimos de DUVERGER, 1959).

\section{Estrategia de investigación}

Dadas las resfricciones de tiempo y las condiciones de complejidad implícitas y especiales que el estudio de este programa debió enfrentar, se escogió la metodología de estudios de caso.

Los estudios de caso son una metodología particular que responde a ciertas necesidades de investigación y que guarda sus propias especificidades (véase ARELLANO, 1996).

El primer elemento que hay que considerar es que los estudios de caso forman parte de los métodos inductivos. Una de las concepciones más conocidas pero equivocadas es suponer que los argumentos deductivos proceden de lo general a lo particular y que argumentos inductivos proceden de lo específico a lo general. En realidad, un argumento es deductivamente válido si y sólo si es imposible que su conclusión sea falsa mientras que sus premisas son verdaderas. Un argumento es inductivamente sólido si y sólo si es improbable que sus conclusiones sean falsas mientras que sus premisas son ciertas, y además el argumento no es deductivamente válido (véase BARKER, 1957;
Hempel, 1966; JaMEs, 1982; PopPer, 1957, 1962, 1968; ResCher, 1980; SKYRMS, 1966).

En este sentido, los estudios de inducción se realizan ante circunstancias de estudio donde no se pueden establecer argumentos deductivos debido a la complejidad e irregularidad de los elementos y eventos involucrados. Los estudios de inducción elaboran un marco de probabilidad o plausibilidad respecto a una interpretación que no es buena o mala, sino sólo débil o sólida. El proceso de observación donde un evento A es seguido por un evento $B$ en una o varias ocasiones ha sido descrito por Hume (1964 [1886]) como una situación donde es imposible lógicamente seguir de ahí que tal relación sucederá en cualquier otra ocasión.

Los estudios inductivos entonces dependen de la justificación de su interpretación. Cuando se tiene el control de ciertos elementos contextuales y ademâs se busca establecer sustantivamente correlación entre elementos controlados de análisis, entonces hablamos de un estudio inductivo probabilístico (King, 1994). Cuando no se puede establecer el control sobre el contexto y además se busca comprender e interpretar eventos globales, entonces hablamos de un estudio inductivo de plausibilidad (RESCHER, 1980).

Los estudios de caso pertenecen generalmente al segundo tipo de estudios de inducción. Los estudios de caso no buscan correlaciones sino comprensión e interpretación en términos holísticos (YIN, 1989, 1993). Por lo tanto, no descansan en la definición de hipótesis controladas ni de correlaciones probabilísticas, sino en los procesos de sistematización del análisis y eventualmente en preceptos comparativos (RAGIN, 1987).

Los estudios de caso se escogen como estrategia de estudio cuando:

a) el objetivo de la investigación es comprender complejas relaciones causales;

b) no se tiene el control sobre el comportamiento y la situación dificultando el proceso de control de la variación (SMELSER, 1976);

c) se busca un alto nivel de sensibilidad a la complejidad histórica del fenómeno;

d) no se busca comprobar hipótesis basadas en preceptos de simplificación y control sino comprensión sobre fenómenos complejos (YIN, 1989).

La presente investigación escogió la estrategia de estudio de caso y retomó sus elementos metodológicos sustantivos. La elaboración de los guiones de investigación se encontraron en este sentido permanentemente permeados por los requerimientos particulares que esta herramienta de investigación implicó. 


\section{Guión general de la investigación}

\section{Objetivo general}

Realizar un juicio analítico respecto a los resultados y perspectivas del programa de modernización del D.D.F. (19951997)

\section{Método de trabajo}

Estudios de caso (2) de un sector del D.D.F. donde aplicó con éxito (en términos de indicadores de desempeño y continuidad) las estrategias del programa. Se buscó realizar el juicio en términos de dos aspectos: congruencia y perspectivas de institucionalización. El proceso de análisis se llevó a cabo a través de dos procesos de comparación. El primero se dio entre la congruencia de los valores instrumentados en los casos de estudio con los postulados formales del programa de modernización. El segundo, a través de la comparación entre las experiencias o casos de estudio a través de los elementos similares y diferentes que se observaron en términos de cambio cultural de la organización y mecanismos de institucionalización.

\section{Justificación}

Debido al poco tiempo del que se dispuso, el presente estudio pretendió realizar un juicio sustentado en una interpretación plausible a través de la revisión documental, la observación directa y la realización de entrevistas en dos casos donde existía un juicio preliminar de éxito (en términos de indicadores de desempeño y continuidad) tanto por parte de representantes del D.D.F como del grupo de investigación. Estos estudios de caso, sin buscar sustentar una validez externa que permitiera argüir la generalización o representatividad de las observaciones, sin embargo permitió justificar que se realizó una observación de elementos avanzados del programa. Es decir, el juicio de evaluación no persiguió generalizar una tendencia global de éxito o fracaso, sino intentó encontrar la congruencia entre lo buscado y lo alcanzado y observar si existían las posibilidades y potencialidades que permitieran la institucionalización organizacional del programa. Al estudiar casos de avanzada, es de suponer que la tendencia al éxito o al fracaso en ciertos aspectos observados en tales casos de avanzada permitió percibir situaciones sustantivas (muy generales, claro) del programa como un todo.

\section{Supuestos básicos}

Los programas de modemización, vistos como generadores dé cambio en organizaciones, requieren de tiempo y capacidad, primero para sostener el cambio y luego para generar una institucionalización del nuevo orden generado (véanse algunos estudios empíricos sobre el cambio realizados por ALLAIRE y FIRSIROTU, 1992; ASTLEY, 1985; BoOTH, 1991; Crozier, 1991; HINNGS, 1991; MCKINALAY y STARKEY, 1988). Un cambio organizacional puede generar importantes mejoras en los indicadores de desempeño en el corto y mediano plazo y después colapsarse ante una multiplicidad de factores. Aquí el bien conocido caso del gobierno estatal de Minnesota y su programa STEP (Striving Toward Excellence in Performance), documentado en el famoso libro de Barzelay (1992), es importante de considerar. Esta experiencia de cambio y modernización incluso fue premiada como experiencia innovadora por la Fundación Ford y la Universidad de Harvard en 1992. Sin embargo, estudios realizados recientemente indican que la experiencia de cambio comienza a colapsarse y ha fallado en permanecer en el tiempo, es decir, ha fallado en institucionalizarse en términos organizacionales. El cambio organizacional requiere recursos y capacidad para sostenerse y luego para internalizarse por los agentes organizacionales apoyados por nuevos mecanismos organizacionales para su sostenimiento, así como de condiciones contextuales adecuadas para su permanencia. Los símbolos y comportamientos de los actores organizacionales deben cambiar y permanecer. Las estructuras y mecanismos organizacionales de interacción deben sostenerse en la nueva dinámica y sustentarla. Las condiciones contextuales deben favorecer la permanencia y maduración de los efectos del cambio.

\section{Proposición}

Los estudios de caso, como ya se mencionó, no están diseñados metodológicamente para partir y comprobar sobre hipótesis. Esto sería un error metodológico al pretender 1) que se busca entender correlaciones, cuando lo que se quiere es entender la dinámica de un proceso y 2) que se puede controlar la variación de un fenómeno complejo. Para los estudios de caso es preferible establecer proposiciones. Las proposiciones juegan un papel distinto al de las hipótesis en términos metodológicos. Sustantivamente las proposiciones son guías teóricas para observar el fenómeno. Restringen el foco de atención a ciertos elementos que se justifican teóricamente como estratégicos, permitiendo así una sistematización en el manejo de la información. Las conclusiones del estudio de caso pueden y seguramente variarán respecto de la proposición pues no se busca como objetivo de la investigación probar o no tales proposiciones. Para el pre- 
sente estudio la proposición es la siguiente (y dados los límites planteados anteriormente):

Un proceso de modernización como proceso de cambio organizacional no sólo debe mostrar mejora en términos de desempeño en el corto plazo, sino además 1) transformación de valores y simbolos en los actores organizacionales (internalización generalizada de nuevos simbolos) y 2) institucionalización de mecanismos organizacionales que sostienen la permanencia de los nuevos comportamientos de los actores en la organización.

\section{Mecánica de la investigación}

Partiendo de un estudio profundo de la filosofía, estrategias y características del programa de modernización diseñado desde el D.D.F., en el presente estudio se realizarán dos casos de estudio buscando analizar y realizar el juicio sobre los dos elementos que aparecen en la proposición, es decir: internalización de los nuevos símbolos e institucionalización de los mecanismos organizacionales que sostienen la nueva dinámica de comportamiento. Se desarrollarán dos comparaciones: de congruencia entre la lógica formal del programa modernizador y lo instrumentado en los casos de estudio y de contrastación de similitudes y diferencias entre los dos casos de estudio. Los casos que se han escogido analizar (casos del sector desconcentrado y definidos en conjunto con el D.D.F.) permiten una cierta contrastación que enriquecerá el estudio. Se trata de dos casos de naturaleza contextual distinta. En un caso (Álvaro Obregón) se tiene un proceso constante de implementación del programa de modernización. Éste sería el caso "normal». En el otro caso (Venustiano Carranza) se han sufrido dos cambios de autoridades delegacionales y el proceso de modernización y su dinámica se han sostenido. Aquí tenemos un caso donde los cambios permitirán observar más nítidamente la capacidad de los mecanismos de internalización e institucionalización de la dinámica de modernización para sostenerse aun ante cambios importantes en las condiciones (caso de control).

Se realizará a través de tres instrumentos: documentos e indicadores de desempeño ya existentes, entrevistas a los actores involucrados y observación directa de dinámicas y mecanismos organizacionales.

\section{Evidencias}

Para realizar la presente investigación se llevaron a cabo una serie de entrevistas a funcionarios del Sector Central del Departamento del Distrito Federal, así como de las Delegaciones Álvaro Obregón y Venustiano Garranza. De la misma mane- ra se revisaron documentos elaborados por estas dependencias. El número de entrevistas y los servidores a quienes se hicieron se enlistan a continuación:

1) Del Sector Central.

a) Una sola entrevista.

- Oficial Mayor del D.D.F.

- Contralor General del D.D.F.

b) De dos a 5 entrevistas.

- Director General de Modernización Administrativa.

- Director de Simplificación Administrativa.

- Director de Calidad

- Director de Estructuras Orgánicas.

- Coordinador de Reingeniería para el Sector Central.

- Encargado de Indicadores de Desempeño.

- Facilitadores de las Delegaciones Álvaro Obregón y Venustiano Carranza.

c) Seis o más entrevistas.

- Coordinador de Reingeniería para Delegaciones.

2) De las Delegaciones Álvaro Obregón y Venustiano Carranza.

a) Una sola entrevista.

- Subdelegado de Participación Ciudadana de VC.

b) Cuando menos dos entrevistas.

- Líderes de cada uno de los equipos de trabajo en $\mathrm{AO}$ y VC.

- Algún integrante de cada equipo de trabajo en $\mathrm{AO}$ y VC.

c) Tres a seis entrevistas.

- Coordinador de Modemización Administrativa en $\mathrm{AO}$ y VC.

Además de lo anterior, se estuvo presente en al menos dos sesiones de trabajo de cada uno de los equipos de las Delegaciones $\mathrm{AO}$ y VC observando el funcionamiento de dichas reuniones, se siguió físicamente cuando menos un proceso de cada uno de los equipos de ambas Delegaciones. De igual forma, todos los miembros de estos equipos respondieron a un cuestionario elaborado previamente, y se llevaron a cabo más de dos observaciones directas del funcionamiento de las VUD y los CESACs. 
Documentos más importantes del Departamento del Distrito Federal que fueron revisados:

- Acuerdo mediante el cual se establecen facilidades administrativas y subsidios fiscales, para la regularización de las construcciones de inmuebles dedicados a la vivienda.

- Acuerdo mediante el cual se otorgan facilidades administrativas y subsidios fiscales a establecimientos mercantiles y de servicios, para su regularización.

- Acuerdo por el que establece un Procedimiento simplificado de Regularización y que complementa y amplía las facilidades administrativas y los subsidios fiscales para la micro y pequeña industrias, en relación al Acuerdo de la Micro y Mediana empresas publicado en la Gaceta Oficial del Distrito Federal, el 12 de mayo del año en curso. 17 de julio de 1995.

- Acuerdo por el que se crea la Comisión Intersecretarial de Modernización Administrativa del D.D.F. 12 de mayo de 1995. Gaceta oficial del D.F.

- Acuerdo por el que se otorgan subsidios fiscales y facilidades administrativas a las personas físicas o morales que construyan espacios comerciales en el Distrito federal, así como a los comerciantes de vía pública del Centro histórico de la ciudad de México que adquieran los locales de las mismas.

- Acuerdo por que se otorgan subsidios fiscales y facilidades administrativas a las personas físicas, comerciantes de la vía pública, que adquieran locales en el "Mercado de San Ciprián", así como al Fideicomiso constituido para la comercialización y asignación de los locales en el mismo mercado.

- Acuerdo que prorroga la vigencia del diverso publicado en la Gaceta Oficial del D.F. en el número 327 Tomo II, de fecha 4 de septiembre de 1995. 20 de mayo de 1996, gaceta del D.F.

- Acuerdo que tiene por objeto autorizar la creación de Ventanillas Únicas de gestión del Distrito Federal, en las sedes de los organismos empresariales que se ubiquen en esta entidad federativa.

- Acuerdo que tiene por objeto el otorgamiento de facilidades administrativas y subsidios fiscales para la regularización de establecimientos mercantiles que carecen de licencia de uso de suelo, construcción, funcionamiento, o bien de la presentación de la declaración de apertura del giro respectivo.
- Acuerdo que tiene por objeto establecer el procedimiento para la autorización del anteproyecto de Vivienda nueva Licencia (Licencia VIN).

- Acuerdo que tiene por objeto establecer facilidades administrativas para la Regularización y Titulación de Vivienda a cargo de las Entidades Paraestatales del Distrito Federal y de la Tierra (CORETT).

- Acuerdo que tiene por objeto establecer un procedimiento simplificado para otorgar facilidades administrativas y subsidios fiscales, a fin de que se regularicen las Micro y Pequeñas industrias en la materia que se señalan. Gaceta Oficial del D.F. 27 de mayo de 1996.

- Acuerdo que tiene por objeto liberar actividades y establecimientos industriales, mercantiles y de servicios del trámite de autorización de impacto ambiental y precisa los que quedarán sujetos a este trámite.

- Acuerdo que tiene por objeto otorgar facilidades Administrativas y subsidios fiscales para la Regularización de la Micro, Pequeña y Mediana industria.

- Acuerdo que tiene por objeto otorgar facilidades administrativas a fin de que se regularicen los establecimientos mercantiles que carezcan de licencia de funcionamiento o no esté registrada su declaración de apertura y funcionen como restaurantes.

- Acuerdo que tiene por objeto otorgar un plazo de 100 días a diversos establecimientos para que corrijan irregularidades o. subsanen violaciones en las materias que se indican.

- Aviso de declaración de apertura para establecimientos mercantiles.

- Cedillo Hernández Miguel (1996) Tesis de Maestría: La Modernización de la Administración Pública en México. UNAM, Facultad de Ciencias Políticas y Sociales.

- Decreto que reforma diversas disposiciones de la Ley orgánica de la Administración Pública del D.F. Gaceta oficial del D.F. 27 de mayo de 1996.

- Departamento del Distrito Federal (1996) Manual Administrativo de la Delegación Álwaro Obregón. Tomos I y II.

- Departamento del Distrito Federal (1996) Principales Indicadores socioeconómicos y demográficos del D.F.

- Departamento del Distrito Federal. Bases generales para la elaboración del manual de operación de los comités delegacionales de seguridad pública.

- Departamento del Distrito Federal. Desarrollo del análisis y diseño del sistema integral de automatización de trámites. Propuesta de trabajo. Octubre 1995. 
- Departamento del Distrito Federal. Guía de identidad corporativa de VUD.

- Departamento del Distrito-Federal. Guía técnica para la aplicación de la Ley de Procedimiento Administrativo del D.F.

- Departamento del Distrito Federal. Informe de VentaniIlas Únicas delegacionales. Ejercicio, 1996.

- Departamento del Distrito Federal. La dinámica del desarrollo urbano de la Ciudad de México, situación actual y perspectivas.

- Departamento del Distrito Federal. Manual de trámites y servicios al público. Tomo I y II.

- Departamento del Distrito Federal. Manual específico de operación de Ventanilla única.

- Departamento del Distrito Federal. Presentación ejecutiva del Programa de Calidad y Excelencia.

- Departamento del Distrito Federal. Presentación Ejecutiva sobre Desregulación y Simplificación Administrativa.

- Departamento del Distrito Federal. Proceso de (re) diseño de estructuras orgánicas.

- Departamento del Distrito Federal. Proceso de (re) diseño de estructuras orgánicas.

- Departamento del Distrito Federal. Programa de Calidad y Excelencia. Ventanilla Única. Septiembre 1996.

- Departamento del Distrito Federal. Programa de Simplificación Administrativa, Consolidación $y / 0$ fortalecimiento de VUD. Agosto 1996.

- Departamento del Distrito Federal. Reportes de indicadores de los CESACs de las Delegaciones Álvaro Obregón y Venustiano Carranza.

- Departamento del Distrito Federal. Reportes de indicadores de VUD de las Delegaciones Álvaro Obregón y Venustiano Carranza.

- Departamento del Distrito Federal. UNAM. El área rural del D.F.

- Departamento del Distrito Federal.(1995) Programa de Calidad y Excelencia (propuesta).

- Departamento del Distrito Federal.(1997) Programa de Modernización Administrativa. Vertiente Calidad y Excelencia.

- Departamento del Distrito Federal. (1997) Programa de Modernización Administrativa, Programa de Calidad y Excelencia, vertientes calidad y excelencia.
- Docúmentos sobre el Diplomado: Servicios al público y normatividad del D.F.

- Documentos sobre los equipos de rediseño de Procesos de las Delegaciones Álvaro Obregón y Venustiano Carranza.

- Documentos sobre sesiones de trabajo de los equipos de rediseño de las Delegaciones Álvaro Obregón y Venustiano Carranza.

- Estructura Orgánica Básica del DDF.

- Expedición de constancias de uso de suelo.

- Expedición de constancias de zonificación.

- Expedición de licencia de construcción.

- Expedición de licencia de funcionamiento para establecimiento mercantil.

- Expedición de licencias de construcción para la ampliación y/o modificación.

- Expedición de licencias de uso de suelo.

- Folleto mediano sobre Acceso a expedientes, afirmativa ficta y manual de trámites.

- Folleto sobre afirmativa ficta.

- Folleto sobre manual de trámites y servicios al público.

- Formato de Certificación de la Afirmativa ficta. Gaceta Oficial del D.F. 28 de junio de 1996.

- Informes de los equipos de rediseño de procesos de las Delegaciones Álvaro Obregón y Venustiano Carranza.

- Iniciativa de la Ley de Procedimiento Administrativo del D.F. Noviembre de 1995.

- Ley Orgánica de la Administración Pública del D.F. DOF.30 de diciembre de 1996.

- Poster sobre Acceso a expedientes, afirmativa ficta y reglamento de verificación administrativa.

- Poster sobre acceso a expedientes.

- Poster sobre la Ley de procedimientos administrativo.

- Poster sobre trámites que se pueden realizar.

- Programas Operativos Anuales. Delegación Álvaro Obregón y Venustiano Carranza.

- Proyectos y propuestas de la Consultora Arthur d. Little al Departamento del Distrito Federal. Enero 1995.

- Reformas a la Ley Orgánica del D.F. DOF.10 de enero de 1996.

- Reportes de indicadores de la demanda ciudadana de las Delegaciones Álvaro Obregón y Venustianu Carranza 
- Reportes de indicadores de los procesos de trabajo de las Delegaciones Álvaro Obregón y Venustiano Carranza.

- Tríptico sobre el programa de desregulación y simplificación administrativa.

- Tŕptico sobre la Ley de Procedimiento Administrativo.

- Tríptico sobre Ventanilla Única de registro de visto bueno de seguridad y operación.
- Tríptico, expedición de licencias para la realización de espectáculos.

- Tríptico, expedición de licencias, o permisos para la fijación, instalación o colocación de anuncios.

- Tríptico, ventanillas únicas delegacionales.
${ }^{1}$ Para una versión más amplia sobre este trabajo se recomienda consultar el documento Modemización Administrativa de Grandes Metrópolis: Perspectivas y Evaluación del Programa de Modernización del D.D.F. (1995-2000). CIDED.D.F. Esta investigación fue desarrollada principalmente a través de entrevistas, revisión de documentos y observaciones directas. El desglose de esto se puede encontrar en el apéndice metodológico.

'Si bien, en términos formales no fue un programa, en este estudio se le considera como tal debido a que ha sido desarrollado de manera sistemática y mediante una filosofía congruente.

" Una Delegación es una circunscripción territorial dentro del Distrito Federal; la ley le atribuye carácter de órgano desconcentrado de la Administración Pública del Distrito Federal. Actualmente existen dieciséis (Álvaro Obregón, Azcapotzalco, Benito Juárez, Coyoacán, Cuajimalpa de Morelos, Cuauhtémoc, Iztapalapa, Iztacalco, Gustavo A. Madero, Magdalena Contreras, Miguel Hidalgo, Milpa Alta, Tlahuac, Tlalpan, Venustiano Carranza y Xochimilco). Su titular administrativo se conoce como adelegado.

" Para una discusión sobre las transiciones políticas puede consultarse: Jaime F. CárDENAS GRACIA, "Acerca del marco teórico de las transiciones políticas", en Fundación Cambio XXI, Las transiciones a la democracia, México, Porrúa, 1993, pp. 111-135; J.J. LiNz, "Una teoría del régimen autoritario. El caso de España", en La España de los sesenta, Madrid, Moneda y Crédito, 1974, t. III, pp. 1.474-1.553; Ph. SCHMITTER; G. O'DONNELl y L. WhITEHEAD (comps.), Transiciones desde un gobierno autoritario. América Latina, trad. Jorge Piatigorsky, Buenos Aires, Paidós, 1989; Giuseppe DI PALMA, CCómo se democratizan los países o por qué se democratizan los países?s en Fundación Cambio XXI, Las transiciones a la democracia, México, Pomúa, 1993, pp. 13-45.
5 Tomado de D.D.F., Programa de Modernización Administrativa del Departamento del Distrito Federal, mayo de 1997, p. 6 [Documento interno de la Oficialia Mayor del D.D.F.].

${ }^{6}$ Véase Gabriel MocTEZuMA MUÑoz, sLa simplificación y desregulación de la Administración Pública del Distrito Federal, mimeo [Ponencial, p. 6.

" Los aspectos más importantes en la LPA son: principios de procedimiento administrativo, obligatoriedad del Manual de Trámites y Servicios al Público, Procedimiento de revalidación de licencias, la afirmativa ficta y visitas de verificación.

${ }^{3}$ Figura jurídica que implica que el silencio de la autoridad ante una solicitud de autorización, permiso o licencia debe interpretarse en sentido positivo.

'En la Delegación Álvaro Obregón se identificó un quinto proceso: Atención a CENDIs y Bibliotecas.

1i" Debe recordarse que los equipos cambiaron de nombre posteriormente: Control de Gestión pasó a ser atención a la Demanda Ciudadana y Ventanilla Única se convirtió en Resolución de Trámites.

${ }^{11}$ Es conveniente además observar a cada etapa como un proceso en sí misma.

12 Es claro que nos referimos necesariamente a un concepto de autonomía relativa. Ninguna organización gubemamental puede escapar de los marcos legales y nomativos que la generan y sostienen. En este documento se ha entendido por autonomía la capacidad organizacional de enfrentarse y solucionar problemas de los ciudadanos y de la sociedad con sus propias ideas y capacidades de manera eficiente.

\section{Bibliografía}

ALLAIRE, Y. y FIRSIROTU, M., «Revoluciones culturales en las grandes organizaciones• en Cultura organizacional, Bogotá, Legis.

ARELLANo, D. (1996), Case study methods. Analytical bases for social sciences. México, CIDEDT, 46.

ASTLEY, G. (1985), "The two ecologies: population and community perspectives in organziation evolution. En Administrative Science Quarterly, v. 30, pp. 224-238.

BARKER, S. (1957), Induction and bypothesis. Ithaca, Cornell U. Press.

BARZELAY, M. (1992), Breaking through bureaucracy. Berkeley, University of California Press.

Bоотн, S. (1991), ‘La gestion de l'innovation: un modèle général. En Revne Française d'administration publique, París, v. 59, pp. 367-377.
Crozier, M. (1991), -Le changement dans les organisations. En Revue Française d'administration publique, París, v. 59, pp. 349-354.

DUVERGER, M. (1959), An introduction to the social sciences. N.Y., Preager.

HEMPEL, C. (1960), Philosopby of natural science. Englewood Cliff.

HiNINGS, C. et. al. (1991), :Change in an autonomous professional organization. En Joumal of Management Studies, Oxford, vol. 28, pp. 375-393.

HISCH, E. (1967), Validity in interpretation. New Heaven, Yale University Press. Hume, David (1964 [1886]), A treatise of buman nature. Aalen, Scientia Verlag.

JAMES, L. et al. (1982), Causal analysis. Assumptions, models, and data. Beverly Hills, Sage.

KING, G. et al. (1994), Designing social inquiry. Princeton, Princeton U. Press. 
MCKINLAY, A. y STARKEY, K. (1988), “Competitive strategies and organizational change. RAGIN, C. (1986), The comparative method. Berkeley, University of California Press. En Organizationa Studies, Londres, pp. 555-569.

PETTGREW, A. (1979), aOn studying organizational cultures. En Administrative Science Quarterly, v. 24, pp. $570-581$.

POPPER, K. (1968), The logic of scientific discovery. Londres, Hutchinson.

_ (1962), Objective knowledge. An evolutionary approach. Oxford, Clarendon Press.

__(1957), The poverty of bistoricism. New York, Praeger.

PUGH, D. y HICKSON, D. (1976), Organizational structure in its contexts: the Aston Programme I. Londres, Saxon House.
RESCHER, N. (1980), Induction. An essay on the justification of the inductive reasoning. Pittsburgh, U. of Pittsburgh Press.

SkYRMs, B. (1960), An introduction to inductive logic. Belmont, Dickenson Pub.

SMELSER, N. (1976), Comparative methods in social sciences. N.J., Prentice Hall.

YIN, R. (1993), Applications of case study research. Newbury Park, Sage.

(1989), Case study research. Design and methods. Newbury Park, Sage. 